Portland State University

PDXScholar

$11-16-2020$

\title{
Home Resources Supporting Workplace Resources: an Investigation of Moderated Intervention Effects From the Study for Employment Retention of Veterans (SERVe)
}

Sarah Nielsen Haverly

Portland State University

Follow this and additional works at: https://pdxscholar.library.pdx.edu/open_access_etds

Part of the Military and Veterans Studies Commons, and the Psychology Commons Let us know how access to this document benefits you.

\section{Recommended Citation}

Haverly, Sarah Nielsen, "Home Resources Supporting Workplace Resources: an Investigation of Moderated Intervention Effects From the Study for Employment Retention of Veterans (SERVe)" (2020). Dissertations and Theses. Paper 5619.

https://doi.org/10.15760/etd.7491

This Dissertation is brought to you for free and open access. It has been accepted for inclusion in Dissertations and Theses by an authorized administrator of PDXScholar. Please contact us if we can make this document more accessible: pdxscholar@pdx.edu. 
Home Resources Supporting Workplace Resources: An Investigation of Moderated

Intervention Effects from the Study for Employment Retention of Veterans (SERVe)

by

Sarah Nielsen Haverly

A dissertation submitted in partial fulfillment of the requirements for the degree of

Doctor of Philosophy

in

Applied Psychology

Dissertation Committee:

Leslie Hammer, Chair

Todd Bodner

Jennifer Dimoff

Maura Kelly

Portland State University

2020 
(C) 2020 Sarah Nielsen Haverly 


\begin{abstract}
Social support directly impacts psychological outcomes both within the home and work domains (Cohen \& Wills, 1985). Hammer and colleagues (e.g., 2007) suggest that social support at work from supervisors is related to a number of positive workplace outcomes. Kossek et al. (2011) elaborated that social support from supervisors is additionally effective when it is tailored to the unique needs of workers (i.e., role demands). The Veteran Supportive Supervisor Training (VSST; Hammer et al., 2019a, part of the SERVe project) educates supervisors how to better support former service-members employed within the civilian workplace. Additional sources of social support are also key to positive outcomes for workers. Research shows that support from a partner or spouse can impact both home and work outcomes (Tang et a, 2017). Thus, the present study (1) investigated intervention effects of the VSST on both workplace (i.e., job satisfaction, turnover intent, and perceived stress) and home domain (i.e., work-family-conflict and work-family-enrichment) outcomes among a sample of married and partnered workers $(n=406$, a subset of the larger SERVe sample $N=497$ ), and (2) investigated the moderating effect of marriage quality on VSST intervention effects. Investigated through the lenses of Conservation of Resources Theory (COR; Hobfoll, 1989) and Social Support Theory (Cohen \& Wills, 1995), the present study considers strong marriages and domestic partnerships as a resource that contributes to work and work-family outcomes for current and former service members. Results showed that relationship satisfaction did, in fact, moderate the relationship between the training and two home-domain outcomes, though not in the directions
\end{abstract}


hypothesized. Possible explanations and opportunities for further investigation are discussed. 


\section{Dedication}

This dissertation is dedicated to the four people who have most influenced this process: Jocelyn and Albert, the people I have known who loved learning the most. Thank you for the inspiration.

Leslie, the person who offered her support when I thought I could not continue this process. Thank you for the opportunity.

Kyle, the person who has been with me every step of the way. Thank you for absolutely everything. 


\section{Acknowledgments}

This project would not have been possible without the help of many people:

Boundless thanks to my committee for thoughtful feedback and support. Gratitude in particular to Leslie for support and leeway, and the encouragement to get it done. You truly embody supervisor supportiveness.

Thank you to the teachers I've had throughout my life who have inspired me to work hard and love learning: Sally and Gary Winter, Rebecca Wolle, Kaye Smith, Bob Boyd, Joyce Boon, Carmello Bellavia, Anna Marie Medina, and many others.

I am unable to articulate my full gratitude to my parents, Pete and Grace, for their support and love. Thank you to my brothers, Geoff and Sam, for encouragement and humor.

Thank you to Evan and Owen for making it worth it. And to Kyle for unloading the dishwasher for 7 years, and for reminding me that I am more than what I have done or have not. This is yours as much as mine. 


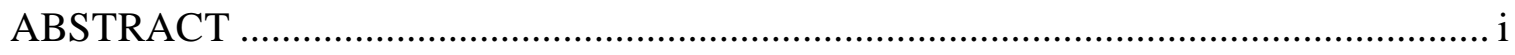

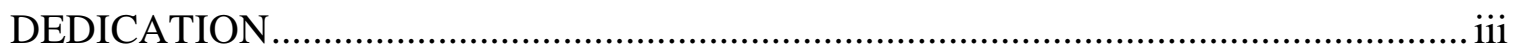

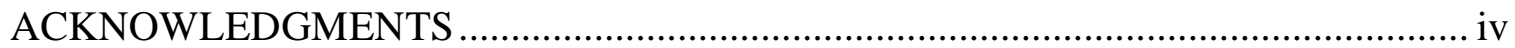

LIST OF TABLES ...................................................................................... vii

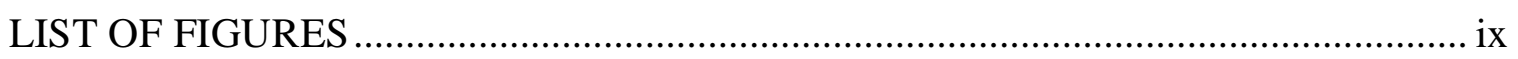

CHAPTER 1: INTRODUCTION ..................................................................... 1

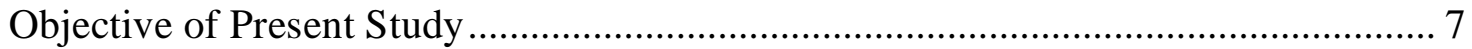

CHAPTER 2: SUPERVISOR SUPPORTIVENESS AND ITS OUTCOMES ............. 10

The Need for Veteran Supportive Supervisor Training ........................................ 10

Job Outcomes .................................................................................................. 16

Work-Family Conflict and Enrichment ................................................................... 19

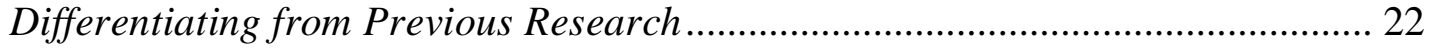

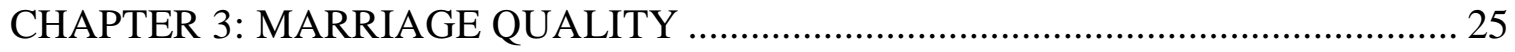

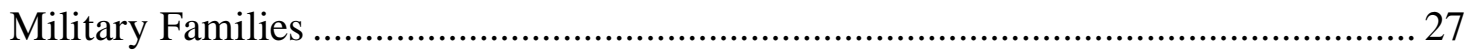

CHAPTER 4: THEORETICAL FRAMEWORK AND HYPOTHESES ..................... 30

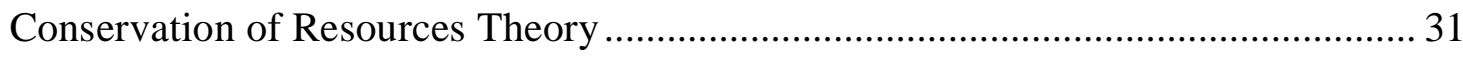

Hypothesized Direct Effects ........................................................................ 33

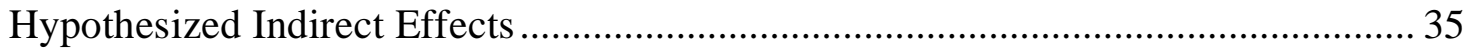

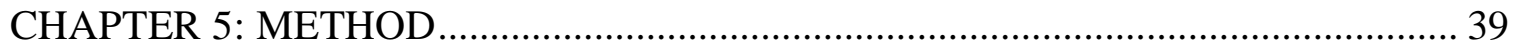

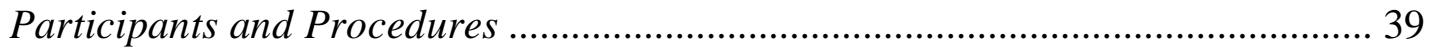

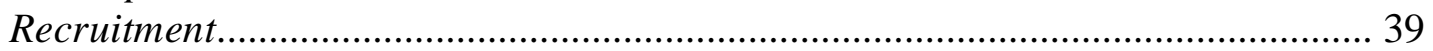

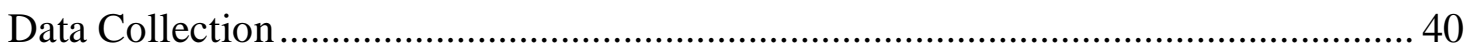

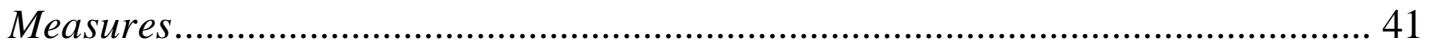

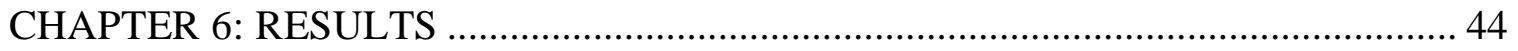

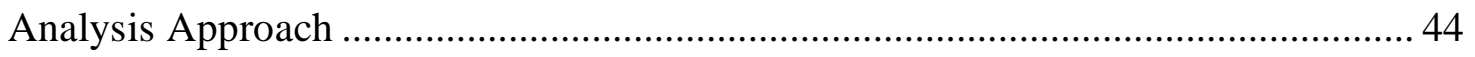

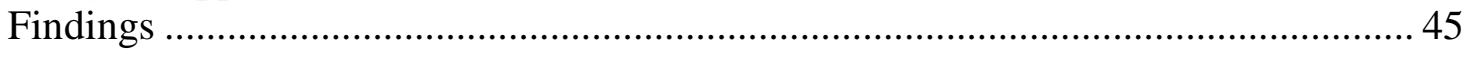

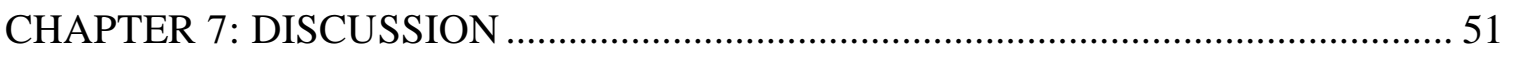

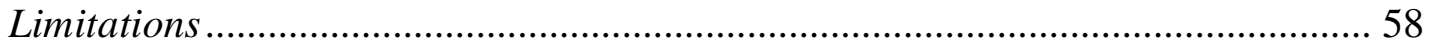

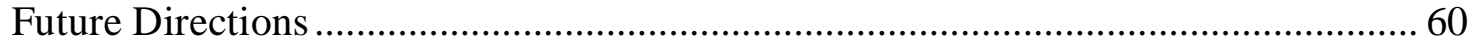

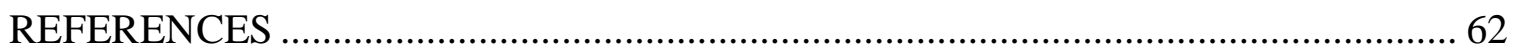

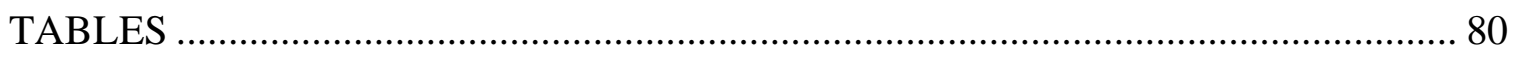

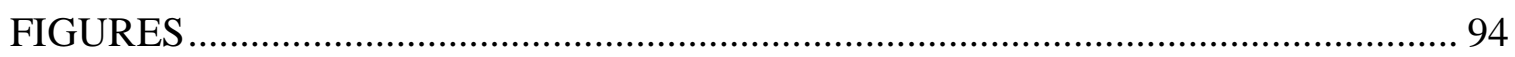

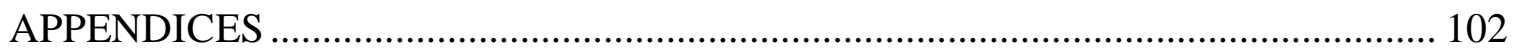


Appendix A: Perceived Stress Scale................................................................... 103

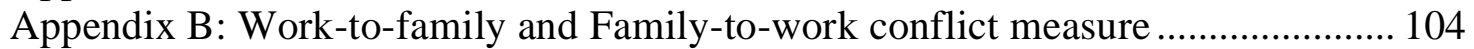

Appendix C: Work-to-family and Family-to-work enrichment measure ................. 105

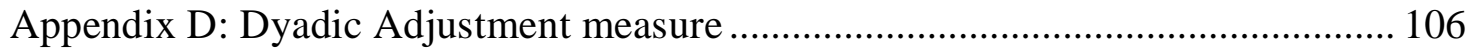




\section{List of Tables}

Table 1: Participant sociodemographic and military demographic information by condition

Table 2: Descriptive statistics of all outcome and moderating variables at baseline, 3 month, and 9 months by condition.

Table 3: Correlations among all outcome and moderating variables at baseline

Table 4: Correlations among all outcome variables at 3 months....

Table 5: Correlations among all outcome variables at 9 months

Table 6: Model results of intervention effects on work domain outcomes at 3-months as moderated by Dyadic Adjustment

Table 7: Model results of intervention effects on work domain outcomes at 9-months as moderated by Dyadic Adjustment. 97

Table 8: Model results of intervention effects on home domain outcomes at 3-months as moderated by Dyadic Adjustment......................................98

Table 9: Model results of intervention effects on home domain outcomes at 9-months as moderated by Dyadic Adjustment .99

Table 10: Model results of intervention effects on work domain outcomes at 3-months as moderated by Relationship Satisfaction

Table 11: Model results of intervention effects on work domain outcomes at 9-months as moderated by Relationship Satisfaction

Table 12: Model results of intervention effects on home domain outcomes at 3-months as moderated by Relationship Satisfaction 
Table 13: Model results of intervention effects on home domain outcomes at 9-months as moderated by relationship satisfaction........................... 103

Table 14: Summary of significant moderated interaction effects..................104 


\section{List of Figures}

Figure 1.0: Conceptual Model Tested by the Proposed Study......................105

Figure 2.0: Representation of SERVe Project Study Design......................106

Figure 3.0 Interaction between condition and baseline relationship satisfaction on work-to-family conflict at 9 -months............................... 107

Figure 4.0: Interaction between condition and baseline relationship satisfaction on work-to-family enrichment at 9 -months............................. 108

Figure 5.0: Interaction between condition and baseline relationship satisfaction on work-to-family enrichment at 9 -months. ...........................109

Figure 6.0: Interaction between condition and baseline dyadic adjustment on family-towork enrichment at 3-months.

Figure 7.0: Interaction between condition and baseline dyadic adjustment on work-to family conflict at 9-months.

Figure 8.0: Interaction between condition and baseline dyadic adjustment on family-towork enrichment at 9-months 


\section{CHAPTER 1: INTRODUCTION}

The American workforce is changing. Not only have the past several decades marked transformations in workforce demographics (e.g., increased diversity), there is also a marked shift in the nature of work (e.g., changes in technology resulting in 24/7 availability). Specifically, the last 30-40 years have seen an increase in work conflicting with non-work life, and vice versa (Hammer \& Zimmerman, 2011). Crain and Stevens (2018) outlined the changing workforce and resulting changing needs of workers. They argue that while organizational policy (as well as national policy) reform is necessary, the front lines of supporting diverse worker needs is with direct supervisors. A rapidly growing body of literature supports the crucial role that supervisors play in supporting the diverse needs of workers.

As work and workers change, so do the resources necessary and available to thrive at work and at home. Conservation of resources theory (COR; Hobfoll, 1989) offers a lens through which to consider benefits in the workplace. COR theory centers around the primary tenet that individuals strive to "obtain, retain, foster, and protect those things that they centrally value", also known as 'resources' (Hobfoll, 2011, p. 128). Hobfoll also states that resources are necessary for the acquisition of more resources (Hobfoll, 1989). A key element of COR theory is the perception of access to, and utility of, resources. Resources are not only defined by their existence, but also, and just as importantly, defined by their usefulness or applicability. Blaisure, Wadsworth, Dombro, Saathoff-Wells and Perieira (2016) use the example of maternity leave benefits within a company; if an organization has rich and generous maternity leave benefits for 
mothers-to-be, this is a resource. However, if there is not also a similar benefit for male employees who become fathers, then this resource is not useful, or applicable, to male employees. Thus, the existence of a resource alone is not enough, but need both be useful and available to an individual. The present study investigates the impact of an added workplace resource in the form of supervisor training to evaluate the applicability of that benefit to specific workers. Through this lens, the present study considered social support as a resource for workers.

Social support is a well-established component of quality of life (Cohen, 2004), and is an important theoretical framework for the present study. Research shows that social support directly impacts both psychological and physical health outcomes, and these processes occur through support in both the home and work domains (Cohen \& Wills, 1985). Hammer and colleagues have demonstrated on numerous occasions (e.g., Hammer, Kossek, Zimmerman, \& Daniels, 2007) that social support at work from supervisors is related to a number of positive workplace outcomes. Specifically, social support from supervisors is especially effective when it is tailored to the unique needs of workers (i.e., role demands; Kossek, et al., 2011).

Crain and Stevens (2018) reviewed social support training for supervisors (FSSB; Hammer, Kossek, Yragui, Bodner, \& Hansen, 2009) and itemize the many impacts of social support at work. These include increased job satisfaction and decreased turnover intentions (e.g., Behson 2005; Breaugh \& Frye, 2007, Hammer et al., 2009, Hammer, Kossek, Bodner, \& Crain, 2013). Social support at work also has direct effects on both health and work-family domain outcomes. FSSB training is 
related to decreased worker stress (Behson, 2005; Thompson \& Prottas, 2006), as well as decreased physical symptoms related to stress (Yragui, Demsky, Hammer, Van Dyck and Neradilek, 2017). In the work-family domain, social support is shown to decrease both work-to-family-conflict as well as family-to-work-conflict (Muse \& Pichler, 2011; Lapierre \& Allen, 2006; Frye \& Breaugh, 2004). While social support has positive impact on workers, research also shows that a lack of social support may have negative consequences.

The present study drew from a sample of married military-connected individuals (separated service members and national guard and reserve members), with particular focus on the moderating effects of marriage quality in the home domain (conceptualized here as a 'home resource') on the impact of a workplace intervention. As with increased social support at work, social support in the family domain is connected to positive outcomes both at home and at work (Burke \& Greenglass, 1999) and meta-analyses demonstrate this to be particularly true for spousal support (MesmerMagnus \& Viswesveran, 2006). While many studies demonstrate that marriage quality relates to increased wellbeing (e.g., Grover \& Helliwell, 2019), and wellbeing can positively impact work (Baptiste, 2008; Shier \& Graham, 2011), more research is necessary to determine if marriage quality has a positive impact on work (as found in Frattaroli, 2006; Tang, Huang, \& Wang, 2017)

While social support has many demonstrated direct effects, social support is also an established moderating variable (e.g., Yragui et al., 2017; Lim, 1996; Vigoda-Gadot \& Talmud, 2010). Supervisor supportiveness moderates many relationships between 
VSST INTERVENTION AND MODERATED EFFECTS

stressors and negative outcomes. For example, Yragui and colleagues (2017) showed supervisor support in particular moderated coworker psychological aggression's impact on work-wellbeing outcomes, such that higher supervisor support protected against the negative outcomes of coworker aggression. Social support from coworkers has also been shown to moderate work variables. Lim (1996) found that supportiveness of coworkers moderated the relationship between job insecurity and job dissatisfaction, indicating that even in the event of job insecurity strong social support from coworkers protected against job dissatisfaction. In the same study, Lim (1996) found that nonwork social support had a similar buffering effect for overall life dissatisfaction. Participants experiencing job insecurity, who also had high non-work social support, did not experience the same life dissatisfaction as did those individuals without support. Vigoda-Gadot and Talmud (2010) found that social support from both supervisors and coworkers moderate the relationship between organizational politics and several job outcomes, including job satisfaction, organizational commitment, stress, and burnout. Indeed, social support even moderates the relationship between stressors and job performance. Work-family conflict often relates to poorer job performance (e.g., Obrenovic, Juanguo, \& Kahn, 2020). However, according to Wang and Tsai, among workers with high social support outside of work, support buffered the negative impact of WFC on performance (Wang \& Tsai, 2014). In addition to social support at work, social support from outside the work domain is critical.

Literature shows that spousal support can particularly impact experiences at work; having a high marriage quality seems to bolster both work satisfaction and 
efficacy (Tang et al., 2017). In fact, social support through marriage is an important factor in enhancing positive experiences and coping with negative ones (Cutrona, 1996). Accordingly, Tang and colleagues (2017) found an indirect relationship between marriage satisfaction and workplace creativity, through resource spillover from family to work. Many studies have supported that the family lives of employees can also serve to enrich their work lives, both directly and indirectly (e.g., Greenhaus \& Powell, 2006; ten Burmmelhuis \& Bakker, 2012).

However, there is still much unknown in the scientific literature. Research shows that individuals with unique needs may experience the benefits and challenges of work differently (e.g., Kossek et al., 2011). While needs vary as widely as individuals themselves, research demonstrates that veteran status impacts job experiences across both the work and family domains (e.g., Hammer, Cullen, Marchand, \& Dezsofi, 2006). Correlational research shows that military veterans may experience significant negative outcomes due to challenges in the civilian workplace. These include decreased job satisfaction, increased job strain and burnout, increased work-family conflict, and decreased perceived health (Smith, Taverna, Fox, Schnurr, Matteo, \& Vogt, 2017). Vinokur, Pierce, Lewandowski-Romps, Hobfoll, and Galea (2011) argue for increased support from organizations, specifically through interventions, to support veterans in the civilian workforce (Vinokur, et al., 2011). These interventions are needed to increase resources for veterans to help them navigate their unique experiences, both at work and at home. 
Transition out of the military is a huge vocational adjustment, particularly with regards to culture-fit and skill applicability in the civilian workforce. Twenty-eight percent of veterans report uncertainty about how to present military skills in a job interview for civilian work (Strauss, 2016), and 41\% report that hiring managers do not understand the value of military skills. Additionally, Morin (2011) reported that of veterans who have served and reintegrated to the civilian workforce since September 11, 2001, a staggering 44\% report experiencing problems and stress associated with their civilian job. Previous literature shows veterans, in particular, benefit from social support interventions (Bliese \& Castro, 2003; Hammer et al., 2019a). Likewise, former service members may be particularly susceptible to lack of social support. Riviere and colleagues studied post-deployment National Guard members and found that soldiers who felt their civilian employers did not support their military connectedness were more likely to experience both depressive and PTSD symptom criteria (Riviere, Kendall-Robbins, McGurk, Castro, \& Hoge, 2011).

Filling the gaps left in previous literature is important to understand and support workers. In particular, it is important to consider how home-domain resources may interact with work-domain resources. For instance, strong marriages are shown to be a resource for current and former service members, both in home and work domains. Service members reporting greater marriage quality experience increased interpersonal connection during deployment (Blaisure, Saathoff-Wells, Pereira, Wadsworth, \& Dombro, 2012), and smoother transitions upon return home for veterans (Theiss \& Knobloch, 2014). It is well established that when individuals have meaningful and 
VSST INTERVENTION AND MODERATED EFFECTS

healthy close relationships, they enjoy greater health and decreased stress (e.g., Cohen, 2004). Through the Conservation of Resources Theory (COR; Hobfoll, 1989), the present study considered strong marriages and domestic partnerships as a resource that would contribute to work and work-family outcomes for current and former service members.

This study addresses known gaps in the literature by examining the moderating effects of marriage quality on the effects of veteran supportive supervisor training on the veterans themselves. It is expected that higher levels of marriage quality at baseline will enhance the supervisor training effects. In doing so, this study expanded the understanding of how family domain factors (i.e., marriage quality) impacts or influence work domain factors. This investigation is needed to increase understanding of how individuals with and without resources across domains may differentially experience the addition of resources at work in the form of supervisor support for transitioning into the workplace.

\section{Objective of Present Study}

This study sought to investigate how veteran civilian workers experience resource gain at work, which is understudied in the literature. Specifically, this study investigated the direct effects of Veteran Supportive Supervisor Training (VSST; Hammer et al., 2019a), as well as the moderating effects of marriage quality on the VSST intervention effectiveness in both work (i.e., job satisfaction, turnover intent, and perceived stress) and work-family domains (i.e., WFC and WFE). Through the Study for Employment Retention of Veterans (SERVe; Hammer, Wan, Brockwood, Mohr, \& 
Carlson, 2017), supervisors received the Veteran Supportive Supervisor Training (VSST; Hammer et al., 2019a). This training was designed to improve veteran experience both at work and home, improving both job related outcomes (e.g., job satisfaction, turnover intent, perceived stress) and work-family outcomes (e.g., work family conflict and enrichment). Hammer et al. (2019a) revealed several moderated effects at nine-months post-training, such asintervention effects on job performance, turnover intentions, perceived health, and functional impairment, as moderated by several forms of social support (i.e., Veteran Supportive Supervisor Behavior [VSSB; Perry, Hammer, Bodner, Anger \& Brockwood, 2018], FSSB [Hammer, et at., 2009], General Supervisor Support [GSS; Yoon \& Lim, 1999], and General Coworker Support [GCS; Caplan, Cobb, French, Harrison \& Pinneau, 1975]). The present study sought to expand the investigation of the moderating effects of social support by directly evaluating the moderating impact of marriage quality on job satisfaction, turnover intent, perceived stress, WFC and WFE. Research shows that strong social support in the home domain has positive outcomes at home and at work (Neal \& Hammer, 2017). Thus, the present study hypothesized that individuals with strong marriages experience greater benefit from the VSST. Specifically, this study will investigate the moderating effects of marital quality on the VSST intervention effects on both work and workfamily outcomes.

The VSST is designed relying on social support theory (Cohen \& Wills, 1985). This theory indicates that stress is reduced, or buffered against, by increased social support from others. Social support also moderates the impact of strain, and can lead to 
VSST INTERVENTION AND MODERATED EFFECTS

increased reported health outcomes (House, 1981). Social support at work specifically moderates the impact of VSST on both work and family outcomes (Hammer et al., 2019a). However, the question of how support at home moderates VSST effects remains unanswered. In this way, the social support derived from a high-quality marriage may provide added benefit to individuals experiencing support in other domains (i.e., work).

The literature clearly demonstrates that social support in the home domain can facilitate positive outcomes in both the work and the family domains (e.g., Neal \& Hammer, 2017). However, there is a gap in the literature investigating how militaryconnected couples' marriage quality moderates experiences of increased support in the work domain. I explored whether military-connected marriages may serve as an additional resource for veterans, and whether the combination of home and work resources may amplify positive outcomes of the VSST, or buffer against negative outcomes. Specifically, this study investigated whether marriage quality moderates the relationship between the VSST and both work domain and work-family domain outcomes for veterans (i.e., job satisfaction, turnover intentions, perceived stress; bidirectional work-family conflict and work-family enrichment, respectively). See Figure 1.0 for the full conceptual model. 
VSST INTERVENTION AND MODERATED EFFECTS

CHAPTER 2: SUPERVISOR SUPPORTIVENESS AND ITS OUTCOMES

The Need for Veteran Supportive Supervisor Training

While it is demonstrated that military-connected individuals may experience different stressors, Hardison, Zaydman, Oluwatola, Saavedra, Bush, Peterson, and Straus (2015) outlined the many skills military personal learn through service, which are directly applicable to civilian jobs. Organizations can improve company outcomes, as well as employee experience, by leveraging veteran skills. To better leverage veteran skillsets in civilian workplaces, supervisors must understand the skills that veterans are able to transfer to non-military work, and how to support veterans in the civilian workforce. Supervisor-focused training can help supervisors understand the value that veterans bring to civilian work (Hammer et al., 2019a). Recognizing this need, Hammer et al. (2019a) developed a veteran-supportive supervisor training (VSST) intervention. Hammer et al. (2019a) evaluated the impact of the VSST on health, work, and family-domain outcomes for veterans in civilian work. The present study sought to expand the investigation of Hammer and colleagues (2019a) VSST training.

The SERVe project (Hammer et al., 2017) drew on work based on Social Support Theory (Cohen \& Wills, 1985; House, 1981), Behavioral Health Leadership (e.g., Gunia, Sipos, LoPresti, \& Adler, 2015), and the Soldier Adaptation Model (Bliese \& Castro, 2003), all of which are explained further in Chapter 4.

Veteran Supportive Supervisor Training (VSST) 
The VSST, created for the SERVe project (Hammer et al., 2017) and investigated in the present study, draws heavily on concepts from Family Supportive Supervisor Behaviors (FSSB; Hammer et al., 2009). Empirical investigation of FSSB has found that supervisor support is essential for integrating work and family, and can lead to improvement in both work and home lives (Hammer Kossek, Anger, Bodner, \& Zimmerman, 2011; Crain \& Stevens, 2018). Drawing on the work of Gunia et al. (2015) and Cohen and Wills (1985), FSSB is a type of domain-specific leadership (the need for which is supported by Kossek and colleagues, 2011), as it teaches leaders specific social support skills to help employees in managing work and life stress specific to the unique circumstances of the worker.

The VSST is designed to improve supervisors' skills supporting workers with military experience, with primary goals of impacting health and work outcomes. The VSST draws on other evidence-based training models (and the empirical testing thereof) designed to improve organizational support for work and family through changes in organizational cultures via supportive managers. These changes impact quality of life, including health and well-being outcomes, for both workers and their families (Hammer et al., 2011; Hammer et al., 2007).

By educating supervisors about the specific strengths and skills veterans bring to the workplace (e.g., team orientation, leadership skills, innovative problem solving, loyalty) as well as some of the unique challenges faced by veterans (e.g., need for flexibility related to military obligations, family needs, consequences of previous military service, such as injury), VSST aims to create a more supportive work 
VSST INTERVENTION AND MODERATED EFFECTS

environment for current and future veterans. A deeper understanding by supervisors of veteran experiences may help to ease transitions following military obligations. Crucial for understanding the impact of VSST is consideration of the need for supervisor education about unique veteran experiences. It is possible that civilian supervisors are often naïve to the experiences of military families, particularly those who have separated from the military. It is not well understood by civilians that the impact of military service lasts far beyond the final separation date.

VSST also helps supervisors understand the unique impact of previous and current military involvement on families. For example, a worker returning from deployment may have increased stress about being absent from family functions; a supervisor aware of this type of experience may be more able to support and accommodate a worker's need for schedule flexibility to ensure being present for a child's sporting event or similar situation.

\section{Intervention}

Separated active duty veterans often return to civilian work, and National Guard and Reservists are frequently returning to the very jobs they held in their dual role as “citizen soldiers." The SERVe project seeks to understand and illuminate these issues and positively impact civilian work life of veterans and NG/Rs. SERVe seeks to train civilian workplace employers and supervisors to better support and utilize veteran employees in the civilian workforce. Drawing on theories of social support and behavioral health leadership, the supervisor training seeks to impact the health and well-being of veterans both at work and at home, as well as employment retention in civilian jobs. 
The SERVe study was developed to specifically address some of the unique challenges that veterans face in the civilian workplace (whether separated active duty, separated National Guard and Reservists, or currently serving National Guard and Reservists. The nature of currently serving active duty responsibility precludes the possibility of maintaining a civilian job, and thus they were excluded from the SERVe project).

This intervention was implemented by first recruiting organizations throughout the Pacific Northwest to participate in a project studying veteran reintegration into the civilian workforce. The organization recruitment team identified companies through personal and professional contacts, attending professional events like veteran job fairs, partnering with organizations to recruit on our behalf, and by targeting organizations and industries known to employ high proportions of service members (e.g., first responders). We presented to many local and state level organizations, including the State Senate Committee for Veterans' Affairs. We also asked participating organizations for recommendations of other businesses (i.e., snowball recruiting). The result was 42 organizations, both public and private, who participated in the study. Recruitment began in fall 2013, data collection began in March 2014 over 9 waves, ending in October 2015.

Randomization to the intervention training or control group occurred at the organizational level. Therefore, all participating veterans within an organization were in the same treatment group as other veterans in their same organization. The target of this intervention was supervisors, and they were provided the intervention training. The VSST is aimed at increasing supervisor supportive behavior toward veteran employees. 
The VSST training content was derived from literature, previous interventions by Hammer and colleagues (e.g., Hammer et al., 2011), and focus groups conducted with veterans and their partners. The training content was reviewed by veterans, veteran advocates, and employers, piloted with partner organizations, and updated accordingly. This training intervention included three parts: 1) a computer based, three-module training including learning verification quizzes, 2) behavior tracking tools to enhance training transfer, and 3) additional optional minimodules on specific topics (e.g., military leave) called "Above and Beyond" activities. Supervisors received invitations to participate via email, created unique login and passwords, and were routed to the online computer-based training platform using cTRAIN software (Northwest Training Education and Assessment, Lake Oswego, OR). cTRAIN is a platform developed for many educational levels and purposes (Anger et al., 2006) and has been successfully used similar studies (e.g., Hammer et al., 2011, 2016). The cTRAIN hosted training was selfpaced and interactive, allowing participants to test their knowledge through required quizzes, and rerouting trainees to original content when quiz questions were missed. Content included text (audio and visual), as well as relevant images and example scenarios presented through role-playing videos (e.g., conversations with employees with and without target behaviors of the training). Modules focused on creating military culture and highlighting positive attributes of veteran employees, the two dimensions of supportive supervisor behavior, and finally, how to implement and track supportive behaviors. 
Following completion of the computer-based training, supervisors were routed to their online behavior tracking dashboard, and invited to track supportive behaviors toward employees over a two week period. Over $70 \%$ of participating supervisors completed some behavior tracking. "Above and Beyond" activities provided three additional training modules. By completing these supervisors were eligible to receive higher levels of VSST certification (i.e., gold, silver, or bronze). Thirty-five percent of supervisors completed some Above and Beyond activities.

VSST is designed to improve work experiences for veterans who have transitioned to the civilian workplace. VSST evaluation studies have demonstrated that the training is capable of improving veteran experiences, which lead to reductions in strain. In turn, veterans experience improvements in their quality of life. As demonstrated by Kossek et al. (2011), domain-specific leadership, such as veteran-supportive leadership, can lead to reductions in turnover intentions and turnover, as well as increases in job satisfaction. The VSST has been linked with similar outcomes that impact veterans, their families, and their employers.

Moderated effects revealed that the intervention was effective for veteran employees, however, those effects were moderated by social support prior to training implementation. These findings were true for supervisor support as measured by General Supervisor Support (Yoon \& Lim, 1999), Family Supportive Supervisor Behaviors (Hammer et al., 2009), and Veteran Supportive Supervisor Behaviors (Perry, et al., 2018). Additionally, coworker support had similar moderating effects (General Coworker Support [Caplan et al., 1975]) support. These findings show that veterans 
who already experienced support from supervisors and coworkers were more likely to benefit from the training. This demonstrates the importance of social support, and highlight the gap filled by the present study. What kinds of social support may bolster these intervention effects? To understand we must first review the direct and moderated outcomes of other social support interventions within the workplace.

\section{Job Outcomes}

While the need for benefits and support unique to worker circumstance (e.g., family supportive benefits and support) have been discussed for many years, the empirical support for these benefits has lagged. Thomas and Ganster (1995) suggested that both family-supportive benefits (e.g., maternity leave) and supportive supervision enhance job outcomes, behaviors and attitudes. Since Thomas and Ganster's 1995 study, investigation of supervisor support at work on job, health, and work-family outcomes has increased. Study of these topics has particularly surged in the last 5 years (see Crain \& Stevens, 2018, for full review).

\section{Job Satisfaction and Turnover Intent}

Allen (2001) found that supervisor support tailored to the unique needs of the worker (e.g., family supportiveness) is associated with increased job satisfaction, decreased turnover intent, and reduced work-family conflict for workers. These findings were above and beyond the impact of supportive supervision and benefit availability. Allen (2001) makes the case that the tailoring of support offered to the specific needs of the worker (i.e., family-support) has additional incremental value above and beyond social support alone. Similar findings have been illuminated over 
VSST INTERVENTION AND MODERATED EFFECTS

time. For example, Frye and Breaugh (2004) found that supervisor supportiveness is related to decreased work-family conflict, which in turn predicted increased job satisfaction among workers. Later, Breaugh and Frye (2007) proposed that reporting to a supportive supervisor was also related to increased job satisfaction, but mediated by decreased work-conflict. However, results showed that there is, in fact, a direct relationship between supervisor supportiveness and increased job satisfaction among workers sampled.

Increased job satisfaction and decreased turnover intent were also related to supervisor supportiveness in Hammer and colleagues' 2009 validation of a measure of Family Supportive Supervisor Behavior. The group found that FSSB behaviors were significantly related to increased job satisfaction and decreased turnover intent above and beyond more general measures of supportiveness from supervisors. This finding, in conjunction with those outlined above, offers support for the efficacy of tailored support (e.g., family supportiveness) above and beyond general social support from supervisors. Odel-Dusseau and colleagues (2012) replicated and extended these findings, supporting FSSB's positive impact increasing job satisfaction and decreasing turnover intent, through the mechanism of changing employee perception of supervisor supportiveness.

There are also many examples of these relationships mediated through other factors. Bagger and Li (2014) found FSSB related to increased job satisfaction and decreased turnover intent, both mediated by leader-member exchange (LMX) quality. Similarly Behson (2005) found FSSB related to increased job satisfaction and 
VSST INTERVENTION AND MODERATED EFFECTS

decreased turnover intent. Thompson and Prottas (2006) found FSSB related to increased job satisfaction and decreased turnover intent, mediated by employee perceived control. Hammer and colleagues (2013) expanded the findings from Hammer et al. (2009) by validating a shorter form measurement of FSSB, articulating an even more succinct relationship between supervisor supportiveness and both decreased turnover intention and increased job satisfaction.

Taken collectively, these findings make a strong case for specific and tailored support for those individuals experiencing unique needs at work. FSSB from supervisors relates to positive outcomes for employees, particularly those with high rates of WFC, or high needs related to family demands. Following this logic, the current study proposes similar findings for Veteran Supportive Supervisor Behavior (VSSB; the target behaviors trained by the VSST) for those employees with the unique needs and experiences related to former military service.

Stress

Similarly, research shows that employee stress is greatly impacted by supervisor supportiveness. Behson (2005) performed an analysis of the relative importance of various formalized means of support (e.g., benefits, paid-time-off, etc.) versus informal means of support (e.g., job flexibility, supportive supervision, etc.). Results showed informal support to be considerably more valuable to employees. Notably, supportive supervision explained significantly more variance in employee outcomes than did formal support. In fact, the authors note that job autonomy, flexibility, and a culture of supportive supervision predicted decreases in employee stress across domains. Behson 
also found informal support related to increased job satisfaction and decreased turnover.

There is evidence of supportive supervision decreasing stress among employees across the literature. Indeed, Hammer et al. (2013) found that even with a more succinct measurement of family specific support (FSSB-SF), perceived stress was reduced in both grocery and information technology workers (IT) whose supervisors received supportiveness training. The authors also saw increased job satisfaction and decreased turnover intention in the same study. Similarly, Thompson and Prottas (2006) found that the availability of family benefits (including family supportive supervision) was related to decreased stress, as well as decreased turnover intentions, and increased overall life satisfaction. Interestingly, Thompson and Prottas (2006) found the relationship between FSSB and stress to be mediated by employee's perceived control, a finding which suggests the empowering nature of this type of supervision.

\section{Work-Family Conflict and Enrichment}

Work-to-family conflict is a key cause of stress for families, and work-to-family enrichment can provide many benefits. Additional challenges arise for individuals managing dual roles, which can further impact outcomes across domains (i.e., at work and at home). WFC also impacts health and wellbeing (Frone, 2003). Greenhaus and Beutell (1985) defined the term to be bidirectional; therefore 'work-family conflict' generically refers both to the ways in which work can conflict with family (i.e., workto-family conflict; WFC) as well as the ways family obligations can conflict with work (i.e., family-to-work conflict; FWC). Gareis, Barnett, Ertel, and Berkman (2009) 
expand the conceptualization; for example, long work hours are related to work-tofamily conflict, whereas high obligations for caring for an aging parent may predict family-to-work conflict. Obviously, these types of conflicts apply heavily to service members, but may also apply to former service members as well. National Guard and Reserve (NG/R) members frequently drill all weekend, and then turn around and work a full day at their civilian workplace on Monday. This leaves little time for self-care or family leisure. Similarly, family-to-work conflict is also present. Current and former service members often report challenges, such as feeling pulled in many directions, particularly following deployment (e.g., missing another family obligation due to work, after having missed many during deployment).

The separate types of conflict are understood to be related to role-related outcomes in the same domain. Gareis et al. (2009) underscore that family-to-work conflict predicts poor work performance, and work-to-family conflict predicts poor family relationships, while both predict decreased well-being. Furthermore, Frone (2003) demonstrates that both types of conflicts are related to decreases in physical and mental health. Work-family conflict is a common concern among both military and civilian couples. Research shows that about half of all individuals report experiencing WFC at least occasionally (Anderson, Coffey, \& Byerly, 2002; Erickson, Martinengo, \& Hill, 2010; Hill, 2005). Additionally, Haddock, Zimmerman, Ziemba, and Curent (2001) reported that among marriage and family therapists, over one-third reported working with couples around work-family balance issues. 
Employee work experiences can have significant impact on the home life, and it is well demonstrated that work can particularly strain marriages. The outcomes of WFC are well reviewed in the literature (for a thorough review see Allen, Herst, Bruck, \& Sutton, 2000). However, the present study focuses on work-family outcomes, and therefore this review explores antecedents of work family conflict and enrichment.

Due to the complexity of reciprocal relationships, it has been challenging for scholars to untangle and determine the antecedents of work-family conflict. A recent meta-analysis by Michel, Kortba, Mitchelson, Clark, and Baltes (2011) examined over 1000 correlations from 178 samples to create a model of the five antecedents of workfamily conflict: work role stressors, work role involvement, work social support, work characteristics, and personality. The current study addresses social support specifically and seeks to expand the literature to investigate how family-domain roles may moderate these relationships.

Allen (2001) showed that employee perceptions of the family-supportiveness directly impacted WFC. That is, employees who perceived the organization to be less supportive experienced more WFC, in addition to other negative outcomes. However, Allen showed that supervisors play a key role, both directly and indirectly. Supervisors are often directly responsible for implementing and enforcing policies and administering benefits; they have an important impact on employee job attitudes and outcomes, like WFC. Allen (2001) also makes the case that supervisors impact employee job attitudes indirectly by shaping how the employee experiences the organization (and thereby the employee's perception of organizational level 
VSST INTERVENTION AND MODERATED EFFECTS

supportiveness). These findings are replicated by Beham, Drobnič, and Präg (2014), who found that both family-supportive organizational culture and family supportive supervisors predicted decreases in WFC (conceptualized as 'Work-Family Interference' in their study of European professional and non-professional workers).

In a series of studies by Breaugh and Frye (Breaugh \& Frye, 2007; Breaugh \& Frye, 2008; Frye \& Breaugh, 2004), researchers tested four family-friendly work practices in relation to reducing WFC. They found that three of the four (i.e., ability to take work home, flexible work hours, and family leave policies) predicted lower WFC. However, workers with family-supportive supervisors were more likely to utilize these policies, as well as report additional reduction of WFC.

\section{Differentiating from Previous Research}

Previous research by Hammer and colleagues (i.e., Hammer et al., 2019a) explored the intervention effects of the VSST. However, this study differentiates itself by limiting this investigation to married and cohabitating partnered individuals only (as opposed to the full sample of workers, which contained unmarried/partnered participants as well). Previous research and theory help justify this choice. Conservation of Resources (COR) theory (Hobfoll, 1989) may explain these processes for individuals with greater social support resources (e.g., marriage), as well as greater responsibilities and obligations in the family domain (e.g., marriage and children; see chapter 4). Additionally, previous research (e.g., Crain \& Stevens, 2018) document the unique needs of individuals with families and the accompanying responsibilities compared to those who do not have such responsibilities. 
VSST INTERVENTION AND MODERATED EFFECTS

However, changes in work-family conflict is not the only outcome of social support at work, and while supportiveness is related to decreased negative outcomes (i.e., WFC), the reverse is also true: support is related to positive outcomes through positive spillover. One such example of positive spillover is the concept of enrichment; both work-to-family enrichment (WFE) and family-to-work enrichment (FWE). Most basically, Greenhaus and Powell define work-family enrichment (WFE) as "the extent to which experiences in one role improve the quality of life in the other role" (Greenhaus \& Powell, 2006, p. 72). They conceptualize this format to investigate how work and family lives can be "allies" rather than "enemies" (language originally proposed by Friedman \& Greenhouse, 2000).

Gareis and colleagues (2009) proposed an interactive model for understanding for work-family conflict as well as work-family enrichment. Their findings, tested with over 2000 participants, demonstrate how work-family enrichment offers additional "explanatory power over work-family conflict alone" (p. 703). Carlson, Kacmar, Wayne, and Grzywacz (2006) indicate that resources from work (to family) may, in fact, be different than those resources from family (to work). Indeed, while there are some resources in common (e.g., mood gains), there are some resources unique to each direction. Work-to-family seems to produce sense of accomplishment (among others), while family-to-work offers improved time management and focus.

Similar to the evidence for the antecedents of WFC, WFE has empirical support for social support antecedents. A recent meta-analysis by Lapierre, Li, Kwan, 
Greenhaus, DiRenzo, and Shao (2018) found that both general and family specific supervisor support were related to enhanced work-family enrichment.

Military literature supports different experiences of married veterans compared to unmarried veterans. Karney and Crown (2007) make the case that military affected marriages are fundamentally different than civilian marriages, even after military service has ended. While there are many reasons for this (e.g., frequent moves, isolation from other family, long distance between the couple, withholding information from each other to protect the other), Karney and Crown posit that this increases both closeness and conflict in many couples. 


\section{CHAPTER 3: MARRIAGE QUALITY}

Marriage quality is an important factor in the lives of married individuals. Some literature suggests that marriage may be the most important factor in a person's life (e.g., Gottman, 2014). However, it is not merely the presence of a partner, but rather the quality of the partnership that matters.

Scholars have not always agreed, however, on how to best define a high-quality marriage, and many different measurements exist (e.g., the Relationship Attribution Measure [RAM; Fincham \& Bradbury, 1992]; the Quality Marriage Index [QMI; Norton, 1983]). Hunsley, Best, Lefebvre, and Vito (2001) state succinctly "One of the perennial assessment issues facing researchers in the fields of marital research and marital therapy research is how best to globally evaluate marriages" (p.325). In recent years, though, evidence has emerged for an evaluation of marriage functioning that is both objective (as reflected by observable behaviors) and subjective (as reflected by feelings and perceptions of the members). Marriage quality is defined by Fincham and Bradbury (1987) as a global evaluation of a relationship across multiple dimensions. These dimensions include both negative and positive aspects (e.g., strain and support), attitudes, and behavioral patterns (Bradbury, Fincham, \& Beach, 2000).

One common measurement in the literature is that of Dyadic Adjustment, originally conceptualized by Spanier (1976). Dyadic adjustment, most basically, measures an individual's perspective of how their intimate relationship is functioning (or adjusting) within the context of life challenges. This measurement includes both ratings of subjective satisfaction (a key element of a high-quality marriage is 
satisfaction with the partnership) and self-report measures of easily observable behaviors and events. Spanier coined this combination of subjective and objective selfreport measurement dyadic adjustment, and his scale became one of the most commonly used measure in the marriage quality literature (Glenn, 1990; Touliatos, Perlmutter, \& Straus, 1990).

In 2001, Hunsley and colleagues empirically evaluated Spanier's (1976) original measure, and created a seven-item short form of dyadic adjustment, which has been validated and used hundreds of times since (Sabourin, Valois, \& Lussier, 2005). Dyadic adjustment (as operationalized by Hunsley and colleagues, as well as in the present study) considers three factors. First, it accounts for the extent to which a couple agrees or disagrees on important relationship tenets (like values, goals, and time spent together). Secondly, it evaluates the frequency of observable behaviors known to enhance marital satisfaction and functioning (i.e., stimulating conversation, collaborative efforts). Lastly, it evaluates the overall subjective perception of marital happiness (Hunsley et al., 2001; for full measurement see Appendix D).

Significant literature focuses on how dyadic adjustment suffers in the wake of stressors for both civilian (Graham, Liu, \& Jeziorski, 2006) and military service members (Gerwitz, Polusny, DeGarmo, Khaylis, \& Erbes, 2010). For instance, particularly among veterans of the Operation Enduring Freedom (OEF) and Operation Iraqi Freedom (OIF) middle eastern conflicts, post-traumatic stress symptoms seem to have particular negative impact on dyadic adjustment (Goff, Crow, Reisbig, \& Hamilton, 2007). However, research also shows that veteran marriages experience high 
degrees of shared values and life philosophy (an element of dyadic adjustment). Allen, Rhoades, Stanley, and Markman (2010) showed that marital quality decreases following deployment was fully mediated by experiences of PTS symptoms.

Like much of the military literature, the focus on marriage is often on negative outcomes in the absence of positive factors. This study seeks to take a positive perspective of high-quality marriages as a resource for veteran workers. By considering high dyadic adjustment as a positive social support resource, the present study considers marital support (as measured by dyadic adjustment) as a possible ingredient for resource gain.

The field of stress and resilience continues to be explored and refined across disciplines, and there is increased commitment to exploring ways that contexts shape stress, coping, and resilience.

\section{Military Families}

While the present study seeks to illuminate experiences related to militaryconnected marriages, there is much already known. Research findings demonstrate that military couples face unique strains compared to civilian couples, but also that marriages serve as a source of support for those challenges. Much research has focused specifically on the evolving experience of marriage and intimate partnerships during and following military service.

Both military and civilian family life can be stressful, and both groups incur the anticipated challenges of everyday life (including the birth of a child, an anticipated life transition like starting school or a new job) However, military families experience a 
VSST INTERVENTION AND MODERATED EFFECTS

host of stressors that are normative for them, but not part of expected life course for non-military families (Wan, Haverly, \& Hammer, 2018). These include lengthy hours (e.g., 48-hour drills), frequent moves, separations, deployments, dangerous work, and potential combat. Additional literature demonstrates that significant worry about the safety of a service member by a spouse, particularly during deployment, is considered normative (Blaisure \& Arnold-Mann, 1992; MacDermid, Samper, Schwarz, Nisha, \& Nyaronga, 2008).

These, and other, experiences increase the burden for military spouses and partners, both during and following service. Much like how the effects of service outlast service itself within an individual, the same can be true within a marriage. Karney and Crown point out that many traits and coping strategies developed during times of trial in military life (e.g., deployment), may in fact prove maladaptive in civilian life contexts (like the above example of censored communication). More research is needed to understand how military impacted families exist and function outside the realm of active duty military experiences, and this study fills a gap of understanding some of these processes for veterans in civilian life. In the discipline of marriage science (as well as family systems science, marriage and family therapy, and social work) research is focused on understanding collective coping strategies. How the couple manages resources together when facing challenges is a key for understanding family systems response to stressors (Boss, 2001; Malia, 2006). In fact, considering the context of the family is one of the most important elements to understand family responses to stress (Boss, 1987, 2006, 2007). To consider the resources a family may 
have available to respond to challenges, research must consider the family's resources, particularly relationship satisfaction, and quality. 


\section{CHAPTER 4: THEORETICAL FRAMEWORK AND HYPOTHESES}

Social support theory indicates, most simply, that we are better able to overcome stress with support from others. Thus, support from others serves as a resource for coping with stressors. Significant evidence indicates that social support has direct effects on stress reduction (e.g., Viswesyaran, Sanchez, \& Fisher, 1999). Additionally, social support leads to improved health outcomes by moderating the relationship between strain and health. Previous literature focuses specifically on how social support from supervisors can benefit many different workplace outcomes (e.g., Hammer at al., 2007; Kossek et al. 2011).

Kossek et al.'s (2011) meta-analysis shows that social support in the workplace is more effective when it is tailored to specific role demands for workers (e.g., family demands). Researchers drew on 115 samples consisting of over 72,000 employees and compared four different types of workplace support including supervisor support. Results found that domain specific supervisor supportiveness (in this case work-family specific) were more strongly related to reductions in work-family conflict than was generalized supervisor support.

These findings informed the current study, and also provided a foundation for the SERVe project. This study investigates the larger SERVe project's goal of offering specific training for supervisors to provide support to veterans based on unique experiences, rather than simply generalized support or basic leadership training.

Finally, the Soldier Adaptation Model (SAM; Bliese \& Castro, 2003) is a metatheoretical framework for conceptualizing and organizing experiences related to 
military stress. This model proposes the relationship between stressors (e.g., role ambiguity and work overload) and strains (i.e., health outcomes, attitudinal outcomes, and performance outcomes), are moderated both by individual moderators (e.g., job involvement) and organizational moderators (e.g., leadership climate). Through this theoretical lens, supervisor support serves as an organizational moderator that can buffer the relationship between stressors and strain. As the social support resource offered as part of the VSST is a domain-specific support (i.e., veteran supportiveness), expected findings from the present study would contribute to the theoretical model of the SAM (Bliese \& Castro, 2003), an argument supported by Hammer et al. (2017).

Crucial for underpinning the present study, one may consider social support as a resource available to workers. Resources are necessary and important for myriad outcomes, both at work and at home. Conservation of Resources Theory also helps explain the processes associated therein.

\section{Conservation of Resources Theory}

According to Conservation of Resources (COR) theory, individuals need resources to acquire resources. Conversely, loss of resources, or the threat thereof, costs resources (Hobfoll, 1989). It is through this lens that researchers must carefully interpret the impact of Interventions. Unfortunately, intervention effects are often muddled and challenging to interpret. The present study proposes the consideration of intervention effects through the lens of COR theory.

COR theory seeks to explain the ways that people seek, invest, and protect resources that are perceived necessary to cope with stress. Hobfoll notes resources play 
many roles in the process of, and individuals' resilience, to stress in the context of both family and community (e.g., work; Hobfoll, 1998; Hobfoll, Dunahoo, \& Monnier, 1995). When resources are lost (or threatened to be lost) it causes stress, and additionally causes individuals to invest resources to maintain the resources they still have. (Hobfoll notes that resource loss has a greater emotional impact than resource gain.)

Additionally, resource loss can occur across levels (individuals, families, communities). When this occurs, it poses a significant hinderance to coping and adaptation as the perceived loss is compounded. For example, among a dual-earner couple, one lost job (i.e., income) is a considerable stressor. However, two lost jobs compound the resource loss. The strength of Hobfoll's (1989) model for the present research is in its framing of individuals as they are imbedded in larger systems (e.g., families, work, military). Within these systems, individuals work to gain, maintain, and protect resources. Additionally relevant for the present study is the way this model conceptualizes social support as an important resource in an individual's life. This is true of social support from different sources (i.e., work domain and family domain). The positive impact of social support is also observed with supervisor supportiveness. Individuals who already have supportive supervisors report increased benefits, while individuals without supportive supervisors report the same or decreased levels of satisfaction (e.g., Hammer et al., 2011; Hammer et al., 2019a). This could be due to many factors. For example, focus on supervisor supportiveness may highlight areas in which an employee believes his or her supervisor to be lacking. Conversely, 
VSST INTERVENTION AND MODERATED EFFECTS

"good" managers (or those who already offer support to employees) may be more likely to learn and take on trainings and transfer the skills. Those who focus on being supportive supervisors take advantage of opportunities to improve and apply those learnings. However, whether due to lack of resources themselves, or perhaps not holding supportiveness as a valuable tenant of supervision, some supervisors do not improve with supervisor training. For instance, some interventions have been observed to be beneficial only to certain groups. One such case is presented in Hammer et al. (2011): researchers evaluated the impact of a family-supportive supervisor training on 239 grocery store employees. Interestingly, results showed that for employees with high family-to-work conflict, the impact of supervisor support training was higher. However, those employees with low family-to-work conflict at baseline saw negative training effects.

The main purpose of this study was to investigate direct and moderated intervention effects of the Veteran Supportive Supervisor Training (VSST). Additionally, I sought to investigate how marriage quality at home may serve as a resource of social support to bolster VSST impacts. I proposed direct effects of the VSST on veteran work-domain outcomes (i.e., job satisfaction, turnover intent, and perceived stress). Additionally I proposed the direct effects of the VSST intervention on Veteran work-family domain outcomes (i.e., work-to-family conflict, family-to-work conflict, work-to-family enrichment, and family-to-work enrichment).

\section{Hypothesized Direct Effects}

\section{Hypothesis 1: Veteran Workplace Outcomes}


VSST INTERVENTION AND MODERATED EFFECTS

Focusing only on married or partnered veterans in the Veteran Supportive Supervisor Training (VSST) intervention group, I hypothesized that workers will experience improvements at 3- and 9-months post intervention in:

a) job satisfaction,

b) turnover intentions (decreased), and

c) perceived stress (decreased).

\section{Hypothesis 2: Veteran Work-Family Outcomes}

Among married or partnered veterans, the VSST intervention will reduce at 3and 9-month post-intervention in:

a) work-to-family conflict and

b) family-to-work conflict,

and will improve

c) work-to-family enrichment and

d) family-to-work enrichment.

According to Hobfoll's COR Theory, individuals need resources in order to gain resources. In turn, individuals who have support may be better able to receive support. Supportiveness, viewed as a resource, may allow individuals to more greatly benefit from other resources. Previous work by Hammer and colleagues (2019a) further this theoretical perspective. For instance, veterans benefitted from VSST only when social support was in place prior to the administration of VSST. The present study seeks to expand those findings to understand how marriage quality may moderate the effects of the intervention on work outcomes (job satisfaction, turnover intent, and perceived stress) and home outcomes (WFC and WFE). Other research has outlined how marriage quality moderates the effects of the intervention on work outcomes. Tang and colleagues (2017) demonstrated that higher quality marriage was related to greater workplace creativity. Similarly, ten Brummelhuis and Bakker (2012) demonstrated that family lives serve to enrich work lives and outcomes. 
Hypothesized Indirect Effects

While these relationships are not simple, nor unilateral, we can rely on this literature to further illuminate how marriage quality at home may moderate intervention effects of the VSST at work. Negative experiences with a spouse or partner (e.g., an argument or disagreement) may impact mood and wellbeing long after such an interaction is complete (Silliman, Stanley, Coffin, Markman, \& Jordan, 2002). Indeed, such interactions may have more lasting impacts depending on the regularity and contentiousness of disagreements (a key factor in defining marriage quality and decaying intimacy). However, having a supportive partner with whom a worker can share a pleasant morning and prepare for the workday may set up a worker for better short term and long-term work outcomes.

As suggested by COR theory, this process of resource loss and gain may spiral, such that poor marriage quality may negatively impact job outcomes, and tension and stress at work may increase WFC and similar, leading to increased conflict in the marriage and reduced support. Conversely, higher marital quality is related to better outcomes at work (e.g., Tang et al., 2017). Success and satisfaction at work may lead to higher quality interactions and positive spillover (Bakker, Westman, Hetty van Emmerik, 2009; Brough, Muller, \& Westman, 2018). Indeed, marital role quality will impact the effects of the VSST on work and well-being outcomes, such that the VSST will be more effective when MRQ is high at baseline.

Bakker, Demerouti, and Burke (2009) found that workaholism negatively impacts relationship satisfaction through work-to-family conflict. However, the authors 
also discussed ways in which workplace interventions for workers may be impacted by (or may impact) relationships in the home domain, supporting the assertion that resources in one domain impact resources in another.

There is significant evidence of the way negative experiences in either the work or home domain spill over into the other. However, there is also evidence that social support, particularly from a spouse, is a resource that can buffer against stress experiences across domains. A study by Beach, Martin, Blum, and Roman (1993) indicated that marital satisfaction was the most significant interpersonal variable for predicting level of negative affect at work, wherein workers reporting higher marital satisfaction also reported lower negative affect. Additional support for this notion comes from an intervention study by Schaer, Bodenmann, and Klink (2008). Researchers demonstrated that a couple's coping intervention significantly improved both reported marriage quality, as well as individual worker outcomes (e.g., burnout; Schaer et al., 2008). They suggest that their findings provide evidence of the importance and value of organizations investing in the health and well-being of the relationships of their employees. These findings indicate that healthy marriages at home result in happier workers at work.

Marriage quality has some of largest impact on mood at work (e.g., Beach et al., 1993), and couples coping intervention improve worker outcomes for a single member (Schaer et al., 2008). Therefore, the present study relies on COR theory to consider marriage quality a resource. Conceptualizing high quality marriage and family-domain social support as a resource allows us to understand that this resource may buffer 
VSST INTERVENTION AND MODERATED EFFECTS

against negative outcomes in the work domain. Additionally, as suggested by the findings of Bakker et al. (2009), the resource of high marriage quality may also enhance resource gain in the work domain. The present study also argues that increased resources (i.e., VSST and high MRQ) leads to greater positive outcomes than does VSST alone (or VSST and low MRQ, which may constitute a resource drain).

Traditionally, psychological and health models have not focused on larger contexts (e.g., Lazarus \& Folkman, 1984). However, Hobfoll and colleagues call for a more ecological understanding of stress resilience. Hobfoll (1998) calls for the consideration of individuals nested within families, nested within social settings. (e.g., Hobfoll, Dunahoo, \& Monnier, 1995). Hobfoll's model focuses on individuals within the context of their families (e.g., marriages) and their larger social settings (e.g., work). This model highlights how crucial meaningful connections with others are in order to access and build resources. Research relying on Hobfoll's model focuses on how social connections affect an individual's ability to capitalize on skills and resources to be resilient in the face of stressors. To more deeply understand how social support through marriage can enhance veteran's civilian work experiences, the present study relies on Conservation of Resources Theory.

Research shows that that high marital quality enhance positive outcomes in the work domain (McNall, Nicklin, \& Masuda, 2010). As informed by theory, the context of a worker is crucial for understanding how they experience resource gain and loss across domains. How does the VSST Intervention impact veteran workplace outcomes (i.e., job satisfaction, turnover intentions, perceived stress) as well as home and quality 
VSST INTERVENTION AND MODERATED EFFECTS

of life outcomes (i.e., Work-Family-Conflict/Family-to-Work-Conflict, and Work-to-

Family-Enrichment / Family-to-Work-Enrichment), in the context of social support at

home (i.e., relationship satisfaction, dyadic adjustment, and perceived social support

from family)?

Hypothesis 3: Veteran Workplace Outcomes

Veteran reported marriage role quality will moderate the relationship between the VSST and workplace outcomes, such that those individuals with higher marital role quality (as measured by satisfaction and dyadic adjustment) will lead to improved outcomes compared to those with low MRQ at 3- and 9months:

a) increased job satisfaction,

b) decreased turnover intentions, and

c) reduced perceived stress.

\section{Hypothesis 4: Veteran Work-Family Outcomes}

Veteran reported marriage quality will moderate the relationship between VSST and work-family domain outcomes at 3-and 9-months, such that those individuals with higher relationship quality (as measured by satisfaction and dyadic adjustment) will see greater changes in
a) decreased work-to-family conflict,
b) decreased family-to-work conflict,
c) increased work-to-family enrichment, and
d) increased family-to-work enrichment. 


\section{CHAPTER 5: METHOD}

Participants and Procedures

The data for the present study were collected as part of the larger Study for Employment Retention of Veterans (SERVe). As previously outlined, the larger goals of the SERVe study included improving the civilian work environment for current and former service members, as well as positively impacting their families. Areas of focus included health and well-being, job satisfaction and job-related attitudes, retention, as well as family and relationship experiences. The SERVe study recruited a total of 497 post-9/11 veterans from 35 organization (Hammer et al., 2017). All participants were employed at least 20 hours a week in civilian employment, and thus included separated active duty (48\%), separated National Guard and Reservists (34\%), and currently serving National Guard and Reservists (18\%). By nature of active duty, those service members are unable to also maintain civilian employment and are thus not included in this study. The sample was $83 \%$ white, $84 \%$ male, with a mean age of 39 years. Fortynine percent reported completing college or technical school, $27 \%$ had some college to technical school, and $19 \%$ had some or completed graduate training. Eighty-two percent of the larger sample were in a married or cohabitating relationship, making them eligible to inclusion in the present investigation, and 59\% reported minor children living at home at least part time.

Recruitment

SERVe project recruitment occurred at the organizational level, as well as the veteran level. A veteran recruitment team focused on reaching out to Oregon National 
Guard members and veterans through service member focused community events, thereby obtaining the name of veteran employing organizations. Simultaneously, the recruitment team also recruited organizations directly. Through networking, collaboration, and advertising, the SERVe team recruited over 42 organizations to administer the VSST within the organization. (Note: These analyses were limited to veterans from 35 organizations, due to those organizations including both participating veteran and supervisor subjects). After recruiting organizations, the recruitment team worked with human resource departments to initiate communication with employees to recruit veterans and determine eligibility and invite participation.

\section{Data Collection}

The data came from the Study for Employment Retention of Veterans (SERVe) project veteran baseline, 3 and 9 month-post training surveys. After researchers recruited both veterans and supervisors, organizations were randomized to treatment or waitlist control groups. (Randomization occurred at the organization level to mitigate possible treatment contamination between supervisors within the same organizations.) All participating veterans completed the baseline (pre-intervention) survey (full SERVe sample, $N=497$; the present study sample of married or partnered veterans, $n=406$ ). Following baseline, treatment group supervisors took the VSST. Three months following baseline veterans were invited to take the same survey, and again at nine months following baseline. Waitlist control group supervisors received the VSST following the 9-month survey data collection. For a visual representation of this design, see Figure 2.0. 
VSST INTERVENTION AND MODERATED EFFECTS

Measures

Veteran Workplace Measures

See table 2 for full descriptive statistics of all measures.

Job Satisfaction: The present research evaluated job satisfaction utilizing the Michigan Organizational Assessment Questionnaire Job Satisfaction Subscale by Cammann, Fichman, Jenkins, \& Klesh (1983; adapted from Hackman \& Oldman, 1975), which includes three items $(\alpha=.88)$. These items are evaluated on a (1) "strongly disagree" to (5) "strongly agree" scale, wherein higher scores reflect higher job satisfaction. The items are "In general, you like working at your job," "In general, you are satisfied with your job," and "You are generally satisfied with the kind of work you do in this job."

Turnover Intention: The present research evaluated turnover intention relying on Boroff and Lewin's (1997) two item measure $(\alpha=.92)$. These items are evaluated on a (1) "strongly disagree" to (5) "strongly agree" scale, wherein higher scores reflect higher turnover intent. The items are "I am seriously considering quitting this company for an alternate employer," and "During the next year, I will probably look for a new job outside this firm."

Perceived Stress: The present research evaluated perceived stress by relying on Cohen, Kamarck, and Mermelstein's (1983) four item measure $(\alpha=.76)$. These items are evaluated on a (1) "never" to (5) "always" scale, wherein higher scores reflect greater perceived stress in the past 30 days. A sample item is "In the last month, how often have you felt confident about your ability to handle your personal problems?" 
VSST INTERVENTION AND MODERATED EFFECTS

Note that two of these items are reverse scored. The full measure can be found in appendix A.

Work-to-Family Conflict and Family-to-Work Conflict: The present research evaluated work-to-family conflict (WTFC) and family-to-work conflict (FTWC) with the Matthews, Kath, and Barnes-Darrell (2010) measure, including three items for each construct ( $\alpha=.72$, and .64, respectively). These items are evaluated on a (1) "almost never" to (5) "almost always" scale, where higher scores reflect greater conflict. A sample WFC item is "I have to miss family activities due to the amount of time I must spend on work responsibilities." A sample FWC item is "I have to miss work activities due to the amount of time I must spend on family responsibilities." The full measure can be found in appendix B.

Work-to-Family Enrichment and Family-to-Work Enrichment: The present research evaluated work-to-family enrichment (WTFE) and family-to-work enrichment (FTWE) with the Carlson et al. (2006) measure, including three items for each construct ( $\alpha=.88$, and .77, respectively).. These items are evaluated on a (1) "strongly disagree" to (5) "strongly agree" scale, where higher scores reflect greater enrichment. A sample WTFE item is "My involvement with work helps me to understand different viewpoints and this helps me be a better family member." A sample FTWE item is "My involvement with my family helps me acquire skills and this helps me be a better worker." The full measure can be found in appendix C.

Marriage Quality Measures 
Relationship Satisfaction: The present research evaluated relationship satisfaction with Spanier's (1976) single item measure. This item is evaluated on a (1) "never" to (6) "all the time" scale, wherein a lower score reflects greater satisfaction. The item is "How often do you discuss, or have you considered divorce, separation, or terminating your relationship?" This item was be reverse coded, such that high scores indicate greater satisfaction (i.e., less consideration of leaving the relationship).

Dyadic Adjustment: The present research evaluated dyadic adjustment with the Hunsley, Best, Lefebvre, and Vito (2001) measure. This 7-item measure assesses shared values (3 items, [1] "always disagree" to [6] "always agree"), pleasantly spent time together (3 items, [1] "never" to [6] "more often"), and an evaluation of overall happiness (1 item, [0] "extremely unhappy" to [6] "perfect"; $\alpha=.88$ ). Higher scores reflect higher dyadic adjustment. The full measure was scored by summing all responses. However, the SERVe project evaluated dyadic adjustment (items 1-6) on a (1) to (6) scale, which differed from the original measure as validated by Hunsley et al., (2001). The Hunsley measure utilized a (0) to (5) scale. As a result, these data were measured with the same range as the Hunsley measure recommends, and for analyses the present study recoded this variable to reflect the validated measurement method used by Hunsley. Then scores were summed for a total out of 36 . The full measure used in the SERVe project can be found in appendix D. Notably, these measures of marriage quality both remained stable across the three timepoints. This suggests both that the intervention did not impact these variables, and thusly changes in these variables over time did not impact 3- and 9-month outcome variables. 
CHAPTER 6: RESULTS

\section{Analysis Approach}

Prior to conducting analyses investigating the present hypotheses, I conducted preliminary analyses, including examinations of internal consistency of measures (alphas), descriptive statistics (means, standard deviations, and correlations, see table 15). The data were examined for accuracy, outliers, and missingness. Participants completed a single survey at three time points. Analyses were conducted in IBM SPSS Statistics version 24. Correlations revealed measures correlating as expected. For example, job satisfaction is significantly negatively correlated with turnover intent. See tables 3-5.

Training intervention effects were evaluated using an intent-to-treat approach, using a general linear modeling in order to account for employee nesting within organization. Three- and 9-month study outcomes were evaluated in separate models.

Based on previous literature the following control variables were used:

Service variables: PTSS, Deployment, Combat Exposure: Much literature has focused on how post-traumatic stress symptoms (and other challenges) vary significantly by combat exposure and number of and lengths of deployment (e.g., Allen, 2001). All three factors are also demonstrated to negatively impact both work outcomes and family outcomes, particularly marriage (e.g., Adler-Baeder, Pittman, \& Taylor, 2006). As a result of this literature the current study will control for these variables.

Family variables: Parental status: Child rearing can add significant challenges to marriage, and also impact work outcomes (Byron, 2005). 
Work variables: Baseline levels of Outcomes of Interest (job satisfaction, perceived stress, turnover intention): A meta-analysis by Fellows, Chiu, Hill and Hawkins (2016) which recommends careful and intentional selection of control variables, and recommend inclusion of baseline levels of outcome variables. Bernerth and Aguinis (2016) also conducted a meta-analysis which recommends controlling for these variables.

Home variables: Baseline levels of outcomes of interest (WFC, WFE): Fellows et al., (2016) recommend controlling for baseline levels of outcome variables in analyses.

Participant demographic variables: Age, gender: The present study controls for these variables as previous literature demonstrates they may account for variation in both work outcomes and family outcomes (e.g., Siders, George, \& Dharwadkar, 2001).

\section{Findings}

Of the 406 veterans in committed cohabitating relationships completing the baseline survey, 227 completed the 3-month follow-up, and 179 completed the 9-month follow-up surveys. Missing data were explored through examination for demographic differences in missingness. Using independent sample t-testing, no sociodemographic differences between the control and intervention groups were identified.

Analyses revealed no significant sociodemographic differences between those who participated in both baseline and three-month surveys $(n=336,82.8 \%)$ and those who did not complete the three-month survey $(n=70,17.2 \%)$. However, there was one sociodemographic difference noted between those who completed both baseline and 
nine-month surveys $(n=291,71.7 \%)$ and those who did not $(n=115,28.3 \%)$ : those who completed the nine-month survey had significantly higher job tenure $(M=6.27$, $S D=6.08)$ than those who $\operatorname{did} \operatorname{not}(M=4.35, S D=5.17), t(396)=-2.93, p<.05$.

When evaluating those who persisted and those who did not complete the threemonth survey, differences were identified in baseline levels of outcome variables. Those who completed the baseline and three-month surveys had significantly higher relationship satisfaction $(M=2.05, S D=1.23)$ that those who did not complete the three-month survey $(M=1.72, S D=.09, t(400)=-2.52, p<.05)$. Additionally, those who completed the baseline survey and three-month survey had significantly higher perceived stress $(M=2.58, S D=.94)$ than those who did not complete the three-month survey $(M=2.29, S D=.78, t(402)=2.61, p<.01)$. Finally, those who completed the three-month survey also had significantly higher WTFC $(M=2.56, S D=.88)$ than those who did not complete the three-month survey $(M=2.81, S D=.84, t(404)=2.22$, $p<.05)$.

Similar patterns were noted when comparing those who completed the ninemonth survey and those who did not. Those who completed the nine-month survey had significantly lower turnover intent $(M=2.03, S D=1.17)$ than those who did not $(M=$ 2.33, $S D=1.33), t(404)=2.31, p<.05$. Those who completed the nine-month survey also had significantly lower perceived stress $(M=2.27, S D=.80)$, and lower WTFC $(M$ $=2.53, S D=.87)$ than those who $\operatorname{did} \operatorname{not}(M=2.55, S D=.87), t(402)=3.37, p=.001$ and $(M=2.79, S D=.87), t(404)=2.72, p<.01$, respectively. Finally, those who completed the nine-month survey also had significantly higher relationship satisfaction 
$(M=1.99, S D=1.20)$ than those who did not complete the nine-month survey $(M=$ $1.69, S D=.87), t(400)=-2.83, p<.01$.

Test of training effects

These analyses did not reveal any significant direct effects of the training on named outcome variables at either 3-month or 9-months. Specifically, no direct training effects were identified on job satisfaction (3-months: $b=.01, S E=.12, p=.97$; 9 months: $b=.03, S E=.11, p=.76)$, turnover intention (3-months: $b=.06, S E=.15, p=$ .69 ; 9-months: $b=-.07, S E=.16, p=.66$ ), or perceived stress (3-months: $b=.04, S E=$ $.08, p=.65$; 9-months: $b=.04, S E=.09, p=.65)$. Thus hypotheses 1 a-c were not supported.

Likewise, analyses did not reveal any direct effects of the training on WTFC (3months: $b=-.10, S E=.08, p=.20$; 9-months: $b=-.12, S E=.10, p=.23)$, FTWC (3months: $b=-.03, S E=.08, p=.69$; 9-months: $b=.06, S E=.10, p=.60)$, WTFE (3months: $b=-.01, S E=.08, p=.89$; 9-months: $b=.02, S E=.10, p=.85)$, or FTWE (3months: $b=-.06, S E=.08, p=.48$; 9-months: $b=-.08, S E=.09, p=.41)$. Thus hypotheses $2 \mathrm{a}-\mathrm{d}$ were also not supported.

Test of Moderated training effects

No significant moderated training outcomes were detected for job outcomes at 3-months. Specifically, dyadic adjustment did not moderate the relationship between the intervention and 3-month job satisfaction ( $b=0.01, S E=0.09, p=.93)$, turnover intent $(b=-.16, S E=.11, p=.16)$, or perceived stress $(b=-.08, S E=.07, p=.23$; full results presented in table 6). Likewise, relationship satisfaction did not moderate the 
relationship between the intervention and 3-month job satisfaction $(b=-.02, S E=.07$, $p=.86)$, turnover intent $(b=-.12, S E=.11, p=.29)$, or perceived stress $(b=.01, S E$ $=.07, p=.83 ;$ full results presented in table 10$)$.

Similar findings were present at 9-months; dyadic adjustment did not moderate the relationship between the intervention and 9-month job satisfaction $(b=-.16, S E$ $=.10, p=.11)$, turnover intent $(b=-.04, S E=.14, p=.78)$, or perceived stress $(b=.04$, $S E=.09, p=.67$; full results presented in table 9). Relationship satisfaction did not moderate the relationship between the intervention and 9-month turnover intent $(b=$ $.12, S E=.14, p=.39)$ or perceived stress $(b=.01, S E=.09, p=.92$; full results presented in table 11). Hypothesis 2b-c was not supported. However, relationship satisfaction did moderate the relationship between the intervention and job satisfaction at 9 months $(b=-.21, S E=.01, p<.05)$, such that those individuals in the control group with higher relationship satisfaction saw the highest levels of job satisfaction. While this moderation is significant, it is not observed in the direction hypothesized, and therefore hypothesis 2 a was not supported.

At the 3-month timepoint dyadic adjustment did not moderate the relationship between the intervention and 3-month WTFC $(b=.03, S E=.08, p=.76)$, FTWC $(b$ $=.04, S E=.08, p=.22)$, or WTFE $(b=.01, S E=.08, p=.86)$. However, dyadic adjustment significantly moderated the relationship between the intervention and 3month FTWE $(b=.18, S E=.08, p<.05$; full results presented in table 6$)$. This indicates that individuals in the intervention group with high reported dyadic adjustment observed the highest levels of FTWE, indicating the combined impact of 
VSST INTERVENTION AND MODERATED EFFECTS

high dyadic adjustment and the intervention was most effective in increasing FTWE.

Thus, hypothesis $4 \mathrm{~d}$ was partially supported.

No moderating effects of relationship satisfaction were present at the 3 -month time point. Relationship satisfaction did not moderate the relationship between the intervention and 3-month WTFC $(b=-.01, S E=.98, p=.86)$, FTWC $(b=-.03, S E=$ $.08, p=.71)$, WTFE $(b=-.03, S E=.08, p=.67)$, or FTWE $(b=-.11, S E=.08, p=$ .17 ; full results presented in table 10).

Moderation effects were different at the 9-month timepoint. Dyadic adjustment did not moderate the relationship between the intervention and 9-month FTWC ( $b=$ $-.09, S E=.08, p=.37)$ or FTWE $(b=.04, S E=.09, p=.47)$. However dyadic adjustment did moderate the relationship between the intervention and 9-month WTFC $(b=.21, S E=.10, p<.05)$ and WTFE $(b=-.24, S E=.10, p<.05$; full results presented in table 7). These findings indicate individuals with higher dyadic adjustment at baseline experiences higher WTFC and lower WTFE in the context of the intervention compared to those with lower baseline dyadic adjustment. As these findings were in the opposite direction hypothesized, hypothesis 4a and c were not supported.

Similarly, Relationship satisfaction did not moderate the relationship between the intervention and 9-month FTWC $(b=-.08, S E=.10, p=.43)$, or FTWE $(b=-.04$, $S E=.09, p=.63 ;$ results presented in table 11$)$. Thus, hypothesis $4 \mathrm{~b}$ and $4 \mathrm{~d}$ were not supported. However, relationship satisfaction moderated the relationship between the intervention and 9-month WTFC $(b=.21, S E=.10, p<.05)$, as well as WTFE $(b=-$ 
$.24, S E=.10, p<.05$; results presented in table 13 and figures 4 and 5 ). These moderated effects indicate that for individuals with lower levels of relationship satisfaction (compared to higher levels) at baseline, the training intervention was related to increases in work-to-family enrichment. As these findings were in the opposite direction hypothesized, hypothesis $4 \mathrm{c}$ was not supported. Conversely, for individuals with higher levels of relationship satisfaction (compared to lower levels) at baseline, the training intervention was related to increases in work-to family conflict. Hypothesis 4a predicted a decrease in WTFC for those with high relationship satisfaction, therefore it was not supported. For a full summary of significant results see table 14. 


\section{CHAPTER 7: DISCUSSION}

All couples experience day-to-day stressors. However, both current and former service members and spouses additionally experience the unique experiences of a militarily affected life. Efforts have been made to support service members and their families, but more research is needed to understand how these individuals experience civilian work following service. Through this study, there is new information about how marriage serves as a contextual backdrop for civilian working veterans.

The present study helped to fill gaps in the current understanding of the experiences of married workers with the unique experience of military service (Hammer et al., 2019a). In particular, this study is one of relatively few (including Hammer et al., 2019a; Hammer et al., 2019b) which evaluated a workplace RCT of a theoretically and empirically informed supervisor training to improve veteran transitions into the workplace. Additionally, this is the only study known that investigated the training in the context of home-domain support variables, in this case marriage quality. This study specifically examined the interaction of home-domain support and work-domain support in the form of supervisor supportive training, and their combined impact on both work and home outcomes. Although no direct effects were observed, some significant moderated effects provide insight into how married workers with military experience may be impacted by the VSST intervention. Moderated effects offer important perspectives on the efficacy and applicability of interventions. 
This study demonstrated that marriage quality moderated the relationship between the VSST intervention and several outcomes at 9-months (again, mirroring the patterns of findings of Hammer et al., 2019a). Among the two tested marriage quality moderators (dyadic adjustment and relationship satisfaction), both had significant effects.

Baseline Dyadic Adjustment Moderation: Baseline levels of dyadic adjustment moderated the relationship between the VSST and three home-domain outcomes: FTWE at 3-months, and both WTFC and WTFE at 9-months (the latter findings mirroring the patterns observed with the relationship satisfaction moderator; see table 14). These results indicate that among those veterans with higher dyadic adjustment at 3-months, the intervention was related to higher levels of FTWE (see figure 6). These findings are consistent with Hammer et al. 2019a, in which those individuals with higher supervisor support at baseline saw greater benefit from the intervention than did those with lower supervisor support at baseline. Additionally, veterans with high dyadic adjustment at baseline experienced increased WTFC and decreased WTFE compared to those with low baseline dyadic adjustment at 9-months post-training (see figure 7 and 8, respectively). These findings support prior conclusions (Hammer et al., 2019a; Hammer et al., 2019b) that context matters, and furthers suggestions in the literature that interventions may be best suited to employees most likely to benefit (e.g., Aguinis, Beaty, Boik, \& Pierce, 2005).

In this case, for those employees for whom dyadic adjustment was low, the VSST was more effective for mitigating WTFC and enhancing WTFE. 
Baseline Relationship Satisfaction Moderation: Relationship satisfaction at baseline moderated the relationship between the VSST and job satisfaction at 9-months post intervention. Individuals in the control group with high levels of relationship satisfaction saw the highest levels of job satisfaction, while control group with low levels of baseline relationship satisfaction saw the lowest levels of job satisfaction (see figure 3). There was no significant difference between those with high and low relationship satisfaction among the intervention group on job satisfaction. This suggests that the VSST may provide some impact to the effect of relationship satisfaction, specifically buffering against the negative impact of low relationship satisfaction on job satisfaction.

Baseline levels of relationship satisfaction also moderated the relationship between the VSST intervention and two home-domain outcomes: WTFC and WTFE at 9months. Individuals in the intervention group with high relationship satisfaction saw the highest levels of WTFC, indicating that the intervention was related to higher WTFC than for those with low relationship satisfaction (see figure 4). Likewise, for individuals with high relationship satisfaction at baseline the intervention is related to decrease in WTFE, while for those individuals with low relationship satisfaction the intervention was related to increases in WTFE (see figure 5). These results suggest that the VSST training is related to increases in WTFC and decreases in WTFE for those individuals with high reported relationship satisfaction at baseline again, not consistent with our hypotheses. 
In summary, this study revealed moderated intervention effects across both workand work-family-domains. Specifically, both relationship satisfaction and dyadic adjustment moderated intervention effects on WTFC, and WTFE at 9-months in directions counter to hypothesizes, such that those individuals with lower relationship satisfaction saw the greatest improvements in the context of the intervention. These findings are consistent with previous work (e.g., Hammer et al., 2019b) which demonstrated that intervention effects may be more impactful for those in poorly functioning work groups, or those individuals with less support. Additionally, relationships satisfaction moderated intervention effects on job satisfaction, at 9-months in directions counter to those hypothesized, demonstrating that those individuals in the control group with high relationship satisfaction saw the highest job satisfaction. Finally, dyadic adjustment moderated intervention effects on FTWE at 3-months in the direction hypothesized such that the combination of the intervention and high dyadic adjustment related to the greatest improvements of FTWE. This finding is consistent with previous work (e.g., Crain \& Stevens, 2018) that demonstrated that increased support intervention at work has increased positive outcomes for workers, including in the context of several moderators.

Numerous studies with similar patterns of findings (e.g., Hammer et al., 2019a; Hammer, Truxillo, Bodner, Pytlovany, \& Richman, 2019b) suggest that preintervention context may have important impact on intervention effects. The same evidence is present in this study, and mirror specifically the pattern of findings by Hammer and colleagues (2019a) in their investigation of the full SERVe participant 
VSST INTERVENTION AND MODERATED EFFECTS

sample. Hammer et al. (2019a) and Hammer et al. (2019b) found support for complex moderation effects. In the 2018 evaluation of the VSST, Hammer and colleagues found moderated effects at 9-months post training, such that social support provided an important context for the VSST effects. Hammer and colleagues found that those in lower functioning work groups benefitted most from an intervention (Hammer et al., 2019b). While hypotheses of the present study were not supported, analyses revealed significant moderation effects, some of which were counter to hypothesized directions, providing some evidence that marriage quality does indeed interact with the VSST training to impact both work- and work-family-domain outcomes.

There are several possible explanations for these complex findings. It is important to note that they mirror patterns observed in previous intervention work (e.g., Hammer et al., 2019a; Hammer et al., 2019b; Hammer et al., 2011), which provide additional clues to these complex relationships. One possible explanation could be that individuals with higher relationship satisfaction and increased support at work (through the VSST) experience increased expectation of work-life separation, or work-life balance. It is possible that the combination of positive support at home and at work might make the experience of the two worlds colliding additionally unpleasant. Another possibility is that those individuals with high relationship satisfaction are more sensitive to work impacting the family, in the case of work-to-family conflict. While these data support neither of those explanations, these findings provide an interesting insight for future researchers to consider when investigating intervention effects in the context of marriage quality. 
Implications for COR Theory: The majority of these findings do not support the elements of COR theory originally conceptualized, although the first finding did (Intervention X Dyadic Adjustment $=$ Increased FTWE), increasing the complexity of these findings. Early work related to COR theory indicates that resources begat more resources in a spiral process (Hobfoll, 1989). I hypothesized that marriage quality and supervisor supportiveness would offer a multiplicative increase of resources, though the results of the present study did not support this. There are several possible explanations.

One possibility is that COR is not refined enough to take into account the complex processes seen here. For example, mediating factors may not be accounted for by COR theory, as recent literature demonstrates. Mediators may play a crucial role in the processes at play, even when considering the context moderators. For example, Zaou, Ma, and Dong (2018) found that empowering supervision decreased negative outcomes of concern for those individuals with high self-efficacy (moderation), but through the process of work engagement (mediation). Similarly, Zhai, Wang, and Weadon (2017) reported that COR theory explained their findings that workplace support predicted increased life satisfaction, but that this relationship was mediated by the experience of thriving at work. In fact, Zhai and colleagues (2017) found that the perception of thriving at work fully mediated the relationship between supervisor supportiveness and life satisfaction. Their work reflects a change from Hobfoll's (1989) early COR work, which indicated that context exploration was crucial. However, several studies published in the last three years indicate that perhaps processes related to resource gain are more powerful than hospitable contexts. 
VSST INTERVENTION AND MODERATED EFFECTS

Another example is offered in the opposite direction (i.e., resource loss) by

Fatima, Majeed, and Shah (2018). Using COR theory as a lens, they hypothesized that aversive leadership would result in reduced job performance. While they found this to be present, the process was fully mediated by decreased psychological capital. These findings present an important consideration for future research related to COR theory, which is that person centered resources (as opposed to contextual ones) serve as powerful explanations of the resource gain and loss process, and indeed fully mediate the relationships between contextual resource and personal outcomes.

Hammer and colleagues found similar patterns of results in their 2011 intervention study and explore the possibility of a "backlash" explanation. Hammer et al. (2011) found that in an intervention of supervisor supportiveness (FSSB, specifically), WFC increased for those individuals with low WFC at baseline, suggesting a "family-friendly backlash." The authors suggest that the intervention may have caused resentment for individuals with low conflict, as company resources and attention were being allocated to support those with high conflict. This resentment is likely related to in and out-group bias, which is present in perceptions of justice related to the availability and utility of workplace benefits (Grover, 1991). Contributions

Several contributions were made by this study. First, this investigation furthered examination of the Veteran Supportive Supervisor Training (VSST; Hammer et al., 2017). This training has demonstrated effects positively helping veterans in the civilian workplace through improvements in perceived health, job performance, and decreased 
VSST INTERVENTION AND MODERATED EFFECTS

turnover intentions (Hammer et al., 2019a). These effects were moderated by initial levels of social support at work (i.e., supervisor and coworker), indicating that those with existing support structures benefit more than those without (and perhaps most in need). This study examined another domain of social support (i.e., marriage) as a possible moderator for enhancing intervention positive impact. While my findings do not support these statements broadly, they do indicate that marriage quality is indeed an important moderator in evaluating intervention efficacy.

It is known that cross-domain experiences greatly impact workers, and this study builds on the work of the SERVe project to explore how contextual factors impact intervention experiences at work. In so doing, the present study helped identify areas to support workers (i.e., though training and relationship support; a need that was articulated by Bakker et al., 2009).

This study also offers progress in the investigation of marriage quality as a moderating experience for both work and work-family outcomes. The present study distinguished the two domains in hypotheses and modeling and found evidence for differential impact.

\section{Limitations}

This study also investigated marriage quality as a moderating factor, as previous literature suggest social support serves as a moderator (e.g., Hammer et al., 2019a). However, as enumerated above, it is also possible that marriage quality could serve a mediating role, that is, this could be the mechanism by which changes in context take hold and make impact. For example, couples with high relationship satisfaction may be 
VSST INTERVENTION AND MODERATED EFFECTS

more likely to share or discuss events taking place at work and this process may be part of the impact. While the present findings do not suggest marriage quality would serve a mediating role here, there are likely other mediating factors for consideration. Future research should investigate how marriage quality, and particularly those personcentered factors related to high quality marriage (communication, supportiveness, collaborative problem solving) may mediate intervention effects.

Another limitation comes in the form of marriage measurement. Marriages are dynamic, complex, and often changing systems (Gottman et al., 1998). It is probable that marriages change over the course of their lifetime. Indeed, marriage quality may experience a change following return from deployment or separation from service (Adler et al., 2011) in the form of either an increase in challenges while the service member reintegrates, or in the form of a honeymoon period while the family is overjoyed to be reunited. While the present study seeks to account for this by controlling for deployment status in analyses, future research could more deeply investigate by exploring the divergence of marriage experiences for service members through the lens of marriage as a resource.

As such, it is possible that the linear nature of the present analyses may be obfuscating possibly curvilinear results. While there is no evidence in these data or in the literature for marriage quality playing a curvilinear role in interactions, intervention effects may indeed have non-linear effects.

Previous literature (Perry et al., 2018) suggest that the experience of active NG/R members may be distinctly different than that of separated active duty or 
separated NG/R veterans. Those individuals who are experiencing multiple roles as both active service member and civilian worker may have unique experiences. Supplemental support may be necessary to support individuals in that particular experience.

Additionally, this worker sample of veterans employed in the civilian workforce may not generalize to other workers without the experience of military service. While other research shows these moderated intervention effects are common, more research is needed to determine whether these specific moderating effects of marriage quality also extend to non-military civilian workers.

\section{Future Directions}

Results from this study may inspire further investigation of the impact of marriage quality across domains. While framing high quality marriage as a resource for workers may be beneficial in understanding the process of stress coping and resilience, it also frames important future directions for employers. Indeed, future research should consider what mediating processes marriage and work-place support may impact (e.g., overall life satisfaction). Emphasis in past research often focuses exclusively on resources for an individual worker in the work domain (e.g., supervisor support, Hammer et al., 2011; coping skills, Van de Klink, Blonk, Schene, \& Van Dijk, 2001; cognitive behavioral interventions, Arends et al., 2012). However, Peeters, Montgomery, Bakker, and Schaufeli (2005) articulately noted "companies are usually quite ready to provide work related training and support to employees, but maybe it's time that organizations also try to provide training and support for non-work-related 
VSST INTERVENTION AND MODERATED EFFECTS

demands" (p. 58). Researchers should also continue to explore how home-domain

resources, such as marriage quality and familial support, relate to positive work- and home-domain experiences for workers. Additionally, this line of investigation may support future intervention opportunities for organizations to support the personal relationships of employees.

\section{Conclusion}

This study offers contributions to research and practice through a fresh perspective of marriage as a resource, rather than only as a source of strain. Marriage is an important and stable source of social support. Deeper understanding of how workers may benefit is needed. The present study also offers new insights into interpretation of effects in intervention sciences by helping illuminate those factors that may aid in improving intervention efficacy. Finally, this study advances theoretical understanding of the civilian work lives of veterans in the context of COR theory, as well as the theories underpinning this VSST training (social support theory, Cohen \& Wills, 1985; Behavioral Health Leadership; and the Soldier Adaptation Model, Bliese \& Castro, 2003). Better understanding of the lives, work, needs, and strengths of our service members and their families allow us to better serve and support those who serve us. 


\section{REFERENCES}

Adler, D. A., Possemato, K., Mavandadi, S., Lerner, D., Chang, H., Klaus, J., ... \& Oslin, D. W. (2011). Psychiatric status and work performance of veterans of Operations Enduring Freedom and Iraqi Freedom. Psychiatric Services, 62, 3946.

Adler-Baeder, F., Pittman, J. F., \& Taylor, L. (2006). The prevalence of marital transitions in military families. Journal of Divorce \& Remarriage, 44(1-2), 91106.

Aguinis, H., Beaty, J. C., Boik, R. J., \& Pierce, C. A. (2005). Effect size and power in assessing moderating effects of categorical variables using multiple regression: A 30-year review. Journal of Applied Psychology, 90, 94-107

Allen, E. S., Rhoades, G. K., Stanley, S. M., \& Markman, H. J. (2010). Hitting home: Relationships between recent deployment, posttraumatic stress symptoms, and marital functioning for Army couples. Journal of Family Psychology, 24(3), 280.

Allen, T. D. (2001). Family-supportive work environments: The role of organizational perceptions. Journal of vocational behavior, 58(3), 414-435.

Allen, T. D., Herst, D. E., Bruck, C. S., \& Sutton, M. (2000). Consequences associated with work-to-family conflict: a review and agenda for future research. Journal of occupational health psychology, 5(2), 278. 
VSST INTERVENTION AND MODERATED EFFECTS

Anderson, S. E., Coffey, B. S., \& Byerly, R. T. (2002). Formal organizational initiatives and informal workplace practices: Links to work-family conflict and job-related outcomes. Journal of Management, 28, 787-810.

Arends, I., Bruinvels, D. J., Rebergen, D. S., Nieuwenhuijsen, K., Madan, I., Neumeyer-Gromen, A., ... \& Verbeek, J. H. (2012). Interventions to facilitate return to work in adults with adjustment disorders. Cochrane database of systematic reviews, (12).

Bagger, J., \& Li, A. (2014). How does supervisory family support influence employees' attitudes and behaviors? A social exchange perspective. Journal of Management, 40(4), 1123-1150.

Bakker, A. B., Demerouti, E., \& Burke, R. (2009). Workaholism and relationship quality: A spillover-crossover perspective. Journal of Occupational Health Psychology, 14(1), 23.

Bakker, A. B., Westman, M., \& Hetty van Emmerik, I. J. (2009). Advancements in crossover theory. Journal of Managerial Psychology, 24(3), 206-219.

Baptiste, N. R. (2008). Tightening the link between employee wellbeing at work and performance. Management decision.

Beach, S. R., Martin, J. K., Blum, T. C., \& Roman, P. M. (1993). Effects of marital and co-worker relationships on negative affect: Testing the central role of marriage. American Journal of Family Therapy, 21(4), 313-323. 
VSST INTERVENTION AND MODERATED EFFECTS

Beham, B., Drobnič, S., \& Präg, P. (2014). The Work-Family Interface of Service Sector Workers: A Comparison of Work Resources and Professional Status across Five European Countries. Applied Psychology, 63(1), 29-61.

Behson, S. J. (2005). The relative contribution of formal and informal organizational work-family support. Journal of Vocational Behavior, 66(3), 487-500.

Bernerth, J. B., \& Aguinis, H. (2016). A critical review and best-practice recommendations for control variable usage. Personnel Psychology, 69(1), 229283.

Blaisure, K. R., \& Arnold-Mann, J. (1992). Return and reunion: A psycho-educational program aboard U.S. Navy Shops. Family Relations, 41(2), 178-185.

Blaisure, K. R., Saathoff-Wells, T., Pereira, A., Wadsworth, S. M., \& Dombro, A. L. (2012). Serving military families in the 21 st century. Routledge.

Blaisure, K., Wadsworth, S. M., Dombro, A. L., Saathoff-Wells, T., \& Pereira, A. (2016). Serving military families: theories, research, and application. New York: Routledge. Retrieved from https://www.routledge.com/Textbooks-in-FamilyStudies/bookseries/FAMILYSTUDIES

Bliese, P. D., \& Castro, C. A. (2003). The soldier adaptation model (SAM): Applications to peacekeeping research. The psychology of the peacekeeper: Lessons from the field, 185-203.

Boroff, K. E., \& Lewin, D. (1997). Loyalty, Voice, and Intent to Exit a Union Firm: A Conceptual and Empirical Analysis. Industrial and Labor Relations Review, 51(1), 50-63. 
VSST INTERVENTION AND MODERATED EFFECTS

Boss, P. (1987). Family stress. In Handbook of marriage and the family (pp. 695-723).

Springer, Boston, MA.

Boss, P. (2001). Family stress management: A contextual approach (2nd ed.). Thousand Oaks, CA: Sage

Bradbury, T. N., Fincham, F. D., \& Beach, S. R. (2000). Research on the nature and determinants of marital satisfaction: A decade in review. Journal of marriage and family, 62(4), 964-980.

Breaugh, J. A., \& Frye, N. K. (2007). An examination of the antecedents and consequences of the use of family-friendly benefits. Journal of Managerial Issues, 35-52.

Breaugh, J. A., \& Frye, N. K. (2008). Work-family conflict: The importance of familyfriendly employment practices and family-supportive supervisors. Journal of business and psychology, 22(4), 345-353.

Brough, P., Muller, W., \& Westman, M. (2018). Work, stress, and relationships: The crossover process model. Australian Journal of Psychology, 70(4), 341-349.

Burke, R. J., \& Greenglass, E. R. (1999). Work-family conflict, spouse support, and nursing staff well-being during organizational restructuring. Journal of occupational health psychology, 4(4), 327.

Byron, K. (2005). A meta-analytic review of work-family conflict and its antecedents. Journal of Vocational Behavior, 67, 169-198.

Cammann, C., Fichman, M., Jenkins, G. D., \& Klesh, J. (1983). "Michigan Organizational Assessment Questionnaire." In S. E. Seashore, E. E. Lawler, P. 
H. Mirvis, \& C. Cammann (Eds.), "Assessing organizational change: A guide to methods, measures, and practices" (pp. 71-138). New York: Wiley-Interscience.

Caplan, R. D., Cobb, S., French, J. R., Harrison, R. V., \& Pinneau, S. R. (1975). Job demands and worker health.

Carlson, D. S., Kacmar, K. M., Wayne, J. H., \& Grzywacz, J. G. (2006). Measuring the positive side of the work-family interface: Development and validation of a work-family enrichment scale. Journal of Vocational Behavior, 68(1), 131-164.

Cohen, S., Kamarck, T., \& Mermelstein, R. (1983). A Global Measure of Perceived Stress. Journal of Health and Social Behavior, 24(4), 385-396.

Cohen, S., \& Wills, T. A. (1985). Stress, social support, and the buffering hypothesis. Psychological Bulletin, 98, 310.

Cohen, S. (2004). Social relationships and health. American Psychologist, 59(8), 676.

Crain, T. L., \& Stevens, S. C. (2018). Family-supportive supervisor behaviors: A review and recommendations for research and practice. Journal of Organizational behavior, 39(7), 869-888.

Cutrona, C. E. (1996). Social support in couples: Marriage as a resource in times of stress (Vol. 13). Sage Publications.

Erickson, J. J., Martinengo, G., \& Hill, E. J. (2010). Putting work and family experiences in context: Differences by family life stage. Human Relations, 63, 955-979.

Fatima, T., Majeed, M., \& Shah, S. Z. (2018). Jeopardies of aversive leadership: a conservation of resources theory approach. Frontiers in psychology, 9, 1935. 
VSST INTERVENTION AND MODERATED EFFECTS

Fellows, K. J., Chiu, H. Y., Hill, E. J., \& Hawkins, A. J. (2016). Work-family conflict and couple relationship quality: A meta-analytic study. Journal of Family and Economic Issues, 37(4), 509-518.

Fincham, F. D., \& Bradbury, T. N. (1987). The assessment of marital quality: A reevaluation. Journal of Marriage and the Family, 797-809.

Fincham, F. D., \& Bradbury, T. N. (1992). Assessing attributions in marriage: the relationship attribution measure. Journal of Personality and Social Psychology, 62(3), 457.

Frattaroli, J. (2006). Experimental disclosure and its moderators: a metaanalysis. Psychological bulletin, 132(6), 823.

Friedman, S. D., \& Greenhaus, J. H. 2000. Allies or enemies? What happens when business professionals confront life choices. New York: Oxford University Press.

Frone, M. R. (2003). Work-family balance. In J. C. Quick \& L. E. Tetrick (Eds.), Handbook of occupational health psychology (pp.143-162). Washington, DC: American Psychological Association.

Frye, N. K., \& Breaugh, J. A. (2004). Family-friendly policies, supervisor support, work-family conflict, family-work conflict, and satisfaction: A test of a conceptual model. Journal of Business and Psychology, 19(2), 197-220.

Gareis, K. C., Barnett, R. C., Ertel, K. A., \& Berkman, L. F. (2009). Work-family enrichment and conflict: Additive effects, buffering, or balance? Journal of marriage and family, 71(3), 696-707. 
VSST INTERVENTION AND MODERATED EFFECTS

Gewirtz, A. H., Polusny, M. A., DeGarmo, D. S., Khaylis, A., \& Erbes, C. R. (2010). Posttraumatic stress symptoms among National Guard soldiers deployed to Iraq: Associations with parenting behaviors and couple adjustment. Journal of consulting and clinical psychology, 78(5), 599.

Glenn, N. D. (1990). Quantitative research on marital quality in the 1980s: A critical review. Journal of Marriage and the Family, 818-831.

Goff, B. S. N., Crow, J. R., Reisbig, A. M., \& Hamilton, S. (2007). The impact of individual trauma symptoms of deployed soldiers on relationship satisfaction. Journal of Family Psychology, 21(3), 344.

Gottman, J. M. (2014). What predicts divorce?: The relationship between marital processes and marital outcomes. Psychology Press.

Gottman, J. M., Coan, J., Carrére, S., \& Swanson, C. (1998). Predicting marital happiness and stability from newlywed interactions. Journal of Marriage and Family, 60, 5-22.

Graham, J. M., Liu, Y. J., \& Jeziorski, J. L. (2006). The dyadic adjustment scale: A reliability generalization meta-analysis. Journal of Marriage and Family, 68(3), 701-717.

Greenhaus, J. H., \& Beutell, N. J. (1985). Sources of conflict between work and family roles. Academy of Management Review, 10, 76 - 88 .

Greenhaus, J. H., \& Powell, G. N. (2006). When work and family are allies: A theory of work-family enrichment. Academy of Management Review, 31, 72-92. 
VSST INTERVENTION AND MODERATED EFFECTS

Grover, S. L. (1991). Predicting the perceived fairness of parental leave policies. Journal of Applied Psychology, 76, 247-255.

Grover, S., \& Helliwell, J. F. (2019). How's life at home? New evidence on marriage and the set point for happiness. Journal of Happiness Studies, 20(2), 373-390.

Gunia, B. C., Sipos, M. L., LoPresti, M., \& Adler, A. B. (2015). Sleep leadership in high-risk occupations: An investigation of soldiers on peacekeeping and combat missions. Military Psychology, 27, 197-211.

Hackman, J. R., \& Oldham, G. R. (1975). Development of the job diagnostic survey. Journal of Applied psychology, 60(2), 159.

Hammer, L. B., Cullen, J. C., Marchand, G. C., \& Dezsofi, J. A. (2006). Reducing the Negative Impact of Work-Family Conflict on Military Personnel: Individual Coping Strategies and Multilevel Interventions. In C. A. Castro, A. B. Adler, \& T. W. Britt (Eds.), The Military Life. Military life: The psychology of serving in peace and combat: The military family (pp. 220-242). Westport, CT: Praeger Security International.

Hammer, L. B., Kossek, E. E., Anger, W. K., Bodner, T., \& Zimmerman, K. (2011). Clarifying work- family intervention processes: The roles of work- family conflict and family supportive supervisor behaviors. Journal of Applied Psychology, 96, $134-150$.

Hammer, L. B., Kossek, E. E., Bodner, T., \& Crain, T. (2013). Measurement development and validation of the Family Supportive Supervisor Behavior 
VSST INTERVENTION AND MODERATED EFFECTS

Short-Form (FSSB-SF). Journal of Occupational Health Psychology, 18(3), $285-296$.

Hammer, L. B., Kossek, E. E., Yragui, N., Bodner, T., Hansen, G. (2009). Development and validation of a multi-dimensional scale of family supportive supervisor behaviors (FSSB). Journal of Management, 35, 837-856.

Hammer, L. B., Kossek, E. E., Zimmerman, K., \& Daniels, R. (2007). Clarifying the construct of family supportive supervisory behaviors (FSSB): A multilevel perspective. In P. L. Perrewé \& D. C. Ganster (Eds.), Research in occupational stress and well-being (Vol. 6, pp. 171-211). Amsterdam, the Netherlands: Elsevier.

Hammer, L. B., Neal, M. B., Newsom, J. T., Brockwood, K. J., \& Colton, C. L. (2005). A longitudinal study of the effects of dual-earner couples' utilization of familyfriendly workplace supports on work and family outcomes. Journal of Applied Psychology, 90(4), 799.

Hammer, L. B., Truxillo, D. M., Bodner, T., Pytlovany, A. C., \& Richman, A. (2019b). Exploration of the impact of organisational context on a workplace safety and health intervention. Work \& Stress, 33(2), 192-210.

Hammer, L. B., Wan, W. H., Brockwood, K. J., Bodner, T., \& Mohr, C. D. (2019a). Supervisor support training effects on veteran health and work outcomes in the civilian workplace. Journal of Applied Psychology, 104(1), 52.

Hammer, L. B., Wan, W. H., Brockwood, K. J., Mohr, C. D., \& Carlson, K. F. (2017). Military, work, and health characteristics of separated and active service 
VSST INTERVENTION AND MODERATED EFFECTS

members from the Study for Employment Retention of Veterans (SERVe). Military Psychology, 29(6), 491-512.

Hammer, L. B. \& Zimmerman, K. L. (2011). Quality of work life. In. S. Zedeck (Ed.), APA handbook of industrial and organizational psychology (Vol. 3, pp. 399431). Washington, DC: American Psychological Association.

Haddock, S. A., Zimmerman, T. S., Ziemba, S. J., \& Curent, L. R. (2001). Ten adaptive strategies for family and work balance: Advice from successful families. Journal of Marital and Family Therapy, 27, 445-458.

Hardison, C. M., Zaydman, M., Oluwatola, T., Saavedra, A. R., Bush, T., Peterson, H., \& Straus, S. G. (2015). 360-degree assessments: Are they the right tool for the US military?. RAND NATIONAL DEFENSE RESEARCH INST SANTA MONICA CA.

Hill, E. J. (2005). Work-family facilitation and conflict, working fathers and mothers, work-family stressors and support. Journal of Family Issues, 26, 793-819.

Hobfoll, S. E. (1989). Conservation of resources: A new attempt at conceptualizing stress. American psychologist, 44(3), 513.

Hobfoll, S. E. (1998). The Plenum series on stress and coping. Stress, culture, and community: The psychology and philosophy of stress. New York, NY, US.

Hobfoll, S. E. (2011). Conservation of resources theory: Its implication for stress, health, and resilience. The Oxford handbook of stress, health, and coping, 127, 147.

Hobfoll, S. E., Dunahoo, C. A., \& Monnier, J. (1995). Conservation of resources and traumatic stress. In Traumatic stress (pp. 29-47). Springer, Boston, MA. 
VSST INTERVENTION AND MODERATED EFFECTS

House, G.S. (1981). Work, Stress, and social support. Redding, MAL Addison-Wesley.

Hunsley, J., Best, M., Lefebvre, M., \& Vito, D. (2001). The Seven-Item Short Form of the Dyadic Adjustment Scale: Further Evidence for Construct Validity. American Journal of Family Therapy, 29(4), 325-335. doi:10.1080/01926180152588734

Karney, B. R., \& Crown, J. S. (2007). Families under stress: An assessment of data, theory, and research on marriage and divorce in the military (Vol. 599). Rand Corporation.

Kossek, E. E., Pichler, S., Bodner, T., \& Hammer, L. B. (2011). Workplace social support and work-family conflict: A meta-analysis clarifying the influence of general and work-family-specific supervisor and organizational support. Personnel Psychology, 64, 289-313.

Lacerenza, C. N., Reyes, D. L., Marlow, S. L., Joseph, D. L., \& Salas, E. (2017). Leadership training design, delivery, and implementation: A metaanalysis. Journal of Applied Psychology, 102(12), 1686.

Lapierre, L. M., \& Allen, T. D. (2006). Work-supportive family, family-supportive supervision, use of organizational benefits, and problem-focused coping: implications for work-family conflict and employee well-being. Journal of occupational health psychology, 11(2), 169.

Lapierre, L. M., Li, Y., Kwan, H. K., Greenhaus, J. H., DiRenzo, M. S., \& Shao, P. (2018). A meta-analysis of the antecedents of work-family enrichment. Journal of Organizational Behavior, 39(4), 385-401. 
VSST INTERVENTION AND MODERATED EFFECTS

Lavee, Y., McCubbin, H. I., \& Olson, D. H. (1987). The effect of stressful life events and transitions on family functioning and well-being. Journal of Marriage and the Family, 857-873.

Lazarus, R. S., \& Folkman, S. (1984). Stress, appraisal, and coping. Springer publishing company.

Lim, V. K. (1996). Job insecurity and its outcomes: Moderating effects of work-based and nonwork-based social support. Human relations, 49(2), 171-194.

MacDermid, S. M., Samper, R., Schwarz, R., Nishida, J., \& Nyaronga, D. (2008).

Understanding and promoting resilience in military families. West Lafayette, IN: Military Family Research Institute.

Malia, J. A. (2006). Basic concepts and models of family stress. Stress, trauma, and crisis, 9(3-4), 141-160.

Matthews, R. a, Kath, L. M., \& Barnes-Farrell, J. L. (2010). A short, valid, predictive measure of work-family conflict: item selection and scale validation. Journal of Occupational Health Psychology, 15(1), 75-90.

McNall, L. A., Nicklin, J. M., \& Masuda, A. D. (2010). A meta-analytic review of the consequences associated with work-family enrichment. Journal of Business and Psychology, 25(3), 381-396.

Mesmer-Magnus, J. R., \& Viswesvaran, C. (2006). How family-friendly work environments affect work/family conflict: A meta-analytic examination. Journal of labor research, 27(4), 555-574. 
Michel, J. S., Kotrba, L. M., Mitchelson, J. K., Clark, M. A., \& Baltes, B. B. (2011). Antecedents of work-family conflict: A meta-analytic review. Journal of organizational behavior, 32(5), 689-725.

Morin, R. (2011). The difficult transition from military to civilian life. Washington, DC: Pew Research Center. Retrieved from www.pewsocialtrends .org/2011/12/08/the-difficult-transition-frommilitary-to-civilian-life/

Muse, L. A., \& Pichler, S. (2011). A comparison of types of support for lower-skill workers: Evidence for the importance of family supportive supervisors. Journal of Vocational Behavior, 79(3), 653-666.

Neal, M. B., \& Hammer, L. B. (2017). Working couples caring for children and aging parents: Effects on work and well-being. Psychology Press.

Norton, R. (1983). Measuring marital quality: A critical look at the dependent variable. Journal of Marriage and the Family, 141-151.

Obrenovic, B., Du Jianguo, A. K., \& Khan, M. A. S. (2020). Work-family conflict impact on psychological safety and psychological well-being: a job performance model. Frontiers in psychology, 11.

Odle-Dusseau, H. N., Britt, T. W., \& Greene-Shortridge, T. M. (2012). Organizational work-family resources as predictors of job performance and attitudes: The process of work-family conflict and enrichment. Journal of occupational health psychology, 17(1), 28. 
VSST INTERVENTION AND MODERATED EFFECTS

Peeters, M.C.W., Montgomery, A.J., Bakker, A.B., \& Schaufeli, W.B. (2005).

Balancing work and home: How job and home demands are related to burnout. International Journal of Stress Management, 12(1), 43-61.

Perry, M. L., Hammer, L. B., Bodner, T. E., Anger, W. K., \& Brockwood, K. J. (2018). Development and Validation of a Veteran-Supportive Supervisor Behavior Measure. Military Behavioral Health, 6(4), 308-316.

Riviere, L. A., Kendall-Robbins, A., McGurk, D., Castro, C. A., \& Hoge, C. W. (2011). Coming home may hurt: Risk factors for mental ill health in U.S. reservists after deployment in Iraq. The British Journal of Psychiatry, 198, 136-142.

Sabourin, S., Valois, P., \& Lussier, Y. (2005). Development and validation of a brief version of the dyadic adjustment scale with a nonparametric item analysis model. Psychological assessment, 17(1), 15.

Schaer, M., Bodenmann, G., \& Klink, T. (2008). Balancing work and relationship: Couples Coping Enhancement Training (CCET) in the workplace. Applied Psychology, 57, 71-89.

Shier, M. L., \& Graham, J. R. (2011). Work-related factors that impact social work practitioners' subjective well-being: Well-being in the workplace. Journal of Social Work, 11(4), 402-421.

Siders, M. A., George, G., \& Dharwadkar, R. (2001). The relationship of internal and external commitment foci to objective job performance measures. Academy of Management Journal, 44(3), 570-579. 
VSST INTERVENTION AND MODERATED EFFECTS

Silliman, B., Stanley, S. M., Coffin, W., Markman, H. J., \& Jordan, P. L. (2002). Preventive interventions for couples.

Smith, B. N., Taverna, E. C., Fox, A. B., Schnurr, P. P., Matteo, R. A., \& Vogt, D. (2017). The role of PTSD, depression, and alcohol misuse symptom severity in linking deployment stressor exposure and post-military work and family outcomes in male and female veterans. Clinical Psychological Science, 5(4), 664-682.

Spanier, G. B. (1976). Measuring dyadic adjustment: New scales for assessing the quality of marriage and similar dyads. Journal of Marriage and the Family, 1528.

Strauss, K. (2016, November 11). How Veterans Adjust to the Civilian Workforce. Forbes. Retrieved from https://www.forbes.com/sites/karstenstrauss/2016/11/11/how-veterans-adjust-tothe-civilian-workforce/\#6d74dc106711

Tang, Y., Huang, X., \& Wang, Y. (2017). Good marriage at home, creativity at work: Family-work enrichment effect on workplace creativity. Journal of Organizational Behavior, 38(5), 749-766.

Ten Brummelhuis, L. L., \& Bakker, A. B. (2012). A resource perspective on the workhome interface: The work-home resources model. American Psychologist, 67(7), 545. 
Theiss, J. A., \& Knobloch, L. K. (2014). Relational turbulence and the post-deployment transition: Self, partner, and relationship focused turbulence. Communication Research, 41(1), 27-51.

Thomas, L. T., \& Ganster, D. C. (1995). Impact of family-supportive work variables on work-family conflict and strain: A control perspective. Journal of Applied Psychology, 80, $6-15$.

Thompson, C. A., \& Prottas, D. J. (2006). Relationships among organizational family support, job autonomy, perceived control, and employee well-being. Journal of Occupational Health Psychology, 11(1), 100-118.

Touliatos, J., Perlmutter, B. F., Strauss, M. A., \& Holden, G. W. (Eds.). (2000). Handbook of family measurement techniques: Abstracts (Vol. 1). Sage.

Van der Klink, J. J., Blonk, R. W., Schene, A. H., \& Van Dijk, F. J. (2001). The benefits of interventions for work-related stress. American journal of public health, 91(2), 270.

Vigoda-Gadot, E., \& Talmud, I. (2010). Organizational politics and job outcomes: The moderating effect of trust and social support. Journal of Applied Social Psychology, 40(11), 2829-2861.

Vinokur, A. D., Pierce, P. F., Lewandowski-Romps, L., Hobfoll, S. E., \& Galea, S. (2011). Effects of war exposure on air force personnel's mental health, job burnout and other organizational related outcomes. Journal of Occupational Health Psychology, 16(1), 3. 
VSST INTERVENTION AND MODERATED EFFECTS

Viswesvaran, C., Sanchez, J. I., \& Fisher, J. (1999). The role of social support in the process of work stress: A meta-analysis. Journal of vocational behavior, 54(2), 314-334.

Walker, A. J. (1985). Reconceptualizing family stress. Journal of Marriage and the Family, 827-837.

Walsh, F. (2002). A family resilience framework: Innovative practice applications. Family Relations, 51(2), 130-137.

Wan, W., Haverly, S. N., \& Hammer, L. (2018). Work, Stress, and Health of Military Couples from a Composite Life Cycle Lens. P.D. Harms \& P.L. Perrewe (Eds.) Research in Occupational Stress and Well-being (Vol. 16): Examining the Stress and Well-being of our Military and Veterans. Emerald Publishing Limited.

Wang, M. L., \& Tsai, L. J. (2014). Work-Family conflict and job performance in nurses: The moderating effects of social support. Journal of Nursing Research, 22(3), 200-207.

Yoon, J., \& Lim, J. (1999). Organizational support in the workplace: The case of Korean hospital employees. Human Relations, 52(7), 923-945

Yragui, N. L., Demsky, C. A., Hammer, L. B., Van Dyck, S., \& Neradilek, M. B. (2017). Linking workplace aggression to employee well-being and work: The moderating role of family-supportive supervisor behaviors (FSSB). Journal of business and psychology, 32(2), 179-196. 
Zhai, Q., Wang, S., \& Weadon, H. (2017). Thriving at work as a mediator of the relationship between workplace support and life satisfaction. Journal of Management \& Organization, 1-17.

Zhou, X., Ma, J., \& Dong, X. (2018). Empowering supervision and service sabotage: A moderated mediation model based on conservation of resources theory. Tourism Management, 64, 170-187. 


\section{Tables}

Table 1

Participant sociodemographic and military demographic information by condition

\begin{tabular}{lcc}
\hline \multicolumn{1}{c}{ Variable } & Training $(n=187-227)$ & Control $(n=141-179)$ \\
\hline Age & $M(S D) / \%$ & $M(S D) / \%$ \\
Male & $38.41(9.48)$ & $39.38(9.14)$ \\
White & $89.3 \%$ & $86.0 \%$ \\
College & $77.5 \%$ & $82.1 \%$ \\
Married & $66.5 \%$ & $64.8 \%$ \\
Number of children at home & $83.3 \%$ & $88.8 \%$ \\
Military Experience & $1.31(1.29)$ & $1.41(1.22)$ \\
Active & & \\
Year active in military & $16.7 \%$ & $19.0 \%$ \\
Officer & $12.38(8.55)$ & $12.66(8.2)$ \\
Time since separation & $19.3 \%$ & $18.4 \%$ \\
Ever deployed & $6.02(3.53)$ & $6.27(3.42)$ \\
Branch & $97.8 \%$ & $93.0 \%$ \\
Army NG & & \\
Air NG & $21.6 \%$ & $22.3 \%$ \\
Army Reserves & $7.5 \%$ & $5.6 \%$ \\
Marine Reserves & $8.4 \%$ & $12.3 \%$ \\
Navy Reserves & $11.0 \%$ & $10.6 \%$ \\
Airforce Reserves & $24.7 \%$ & $20.7 \%$ \\
Coast Guard Reserves & $5.7 \%$ & $3.4 \%$ \\
Army & $.9 \%$ & $0 \%$ \\
Air Force & $11.5 \%$ & $7.3 \%$ \\
Coast Guard & $6.2 \%$ & $7.3 \%$ \\
\hline
\end{tabular}




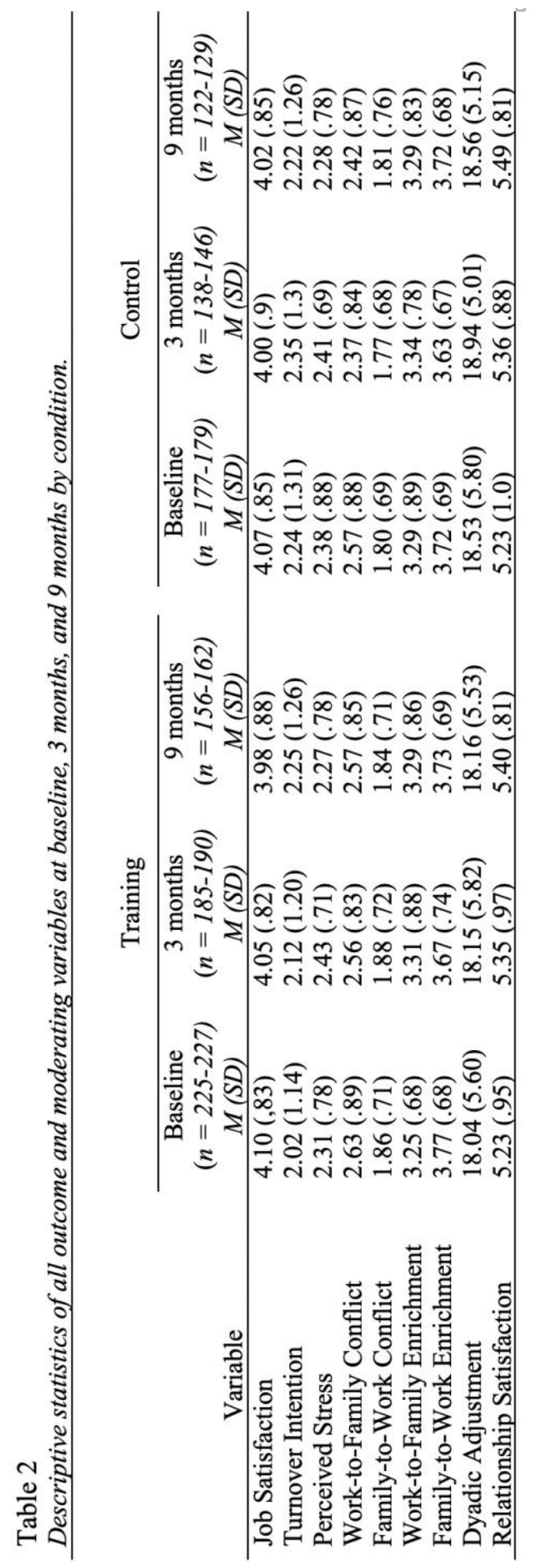




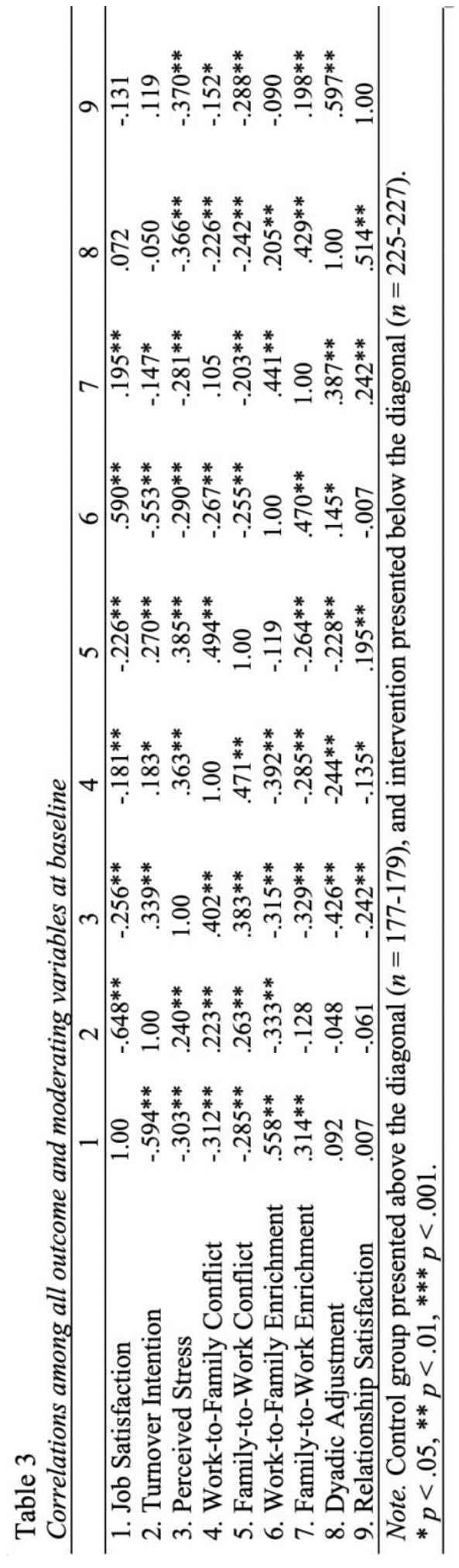




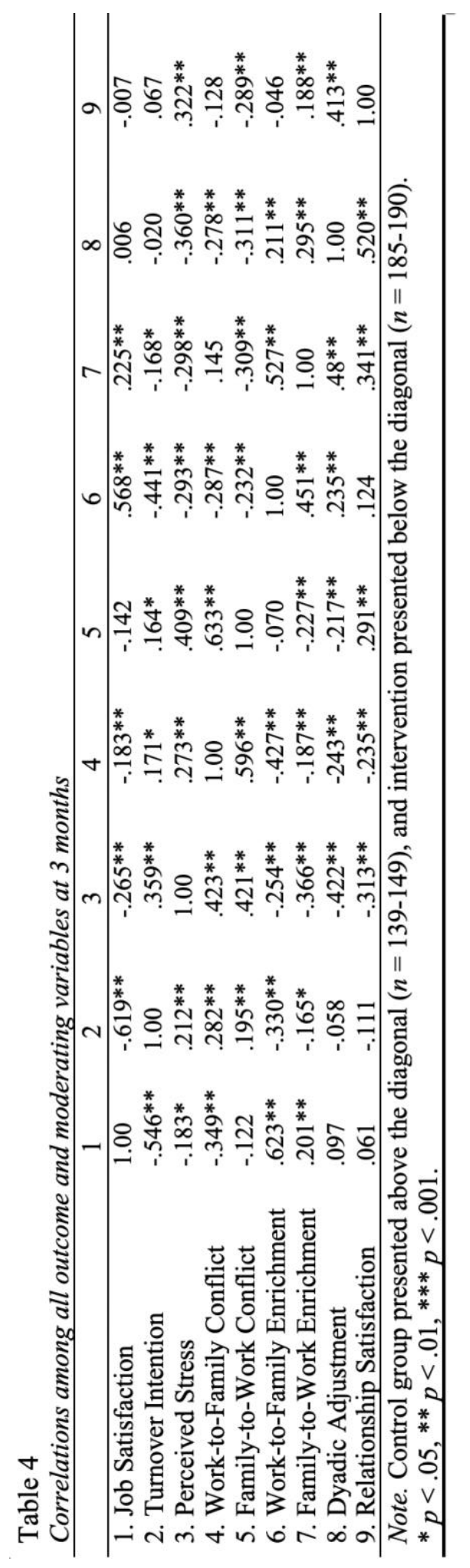




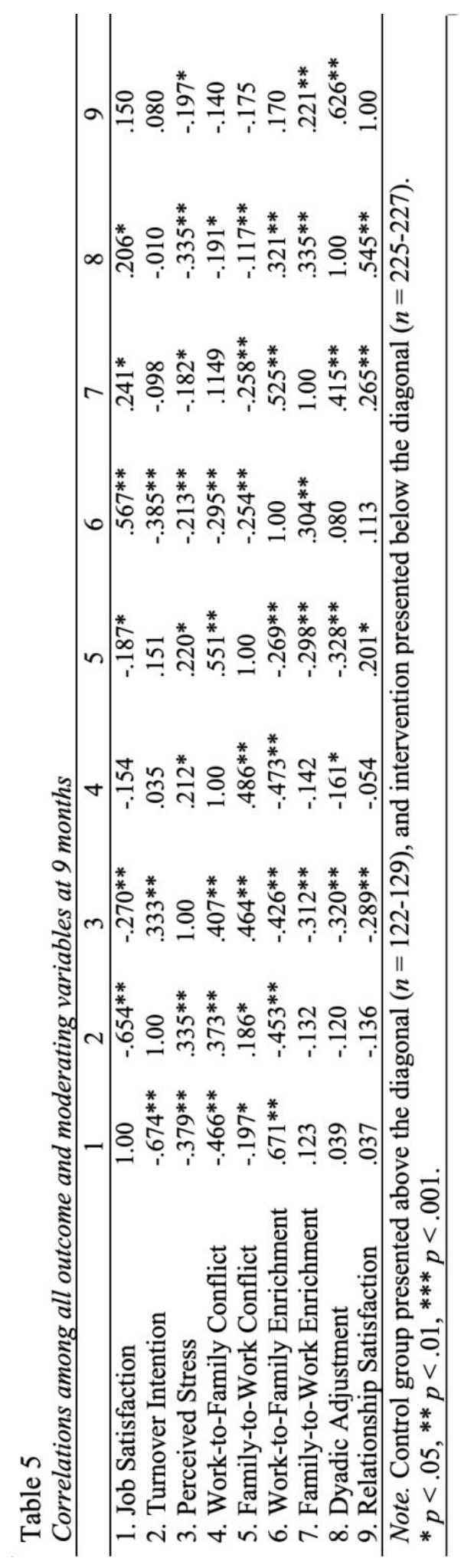




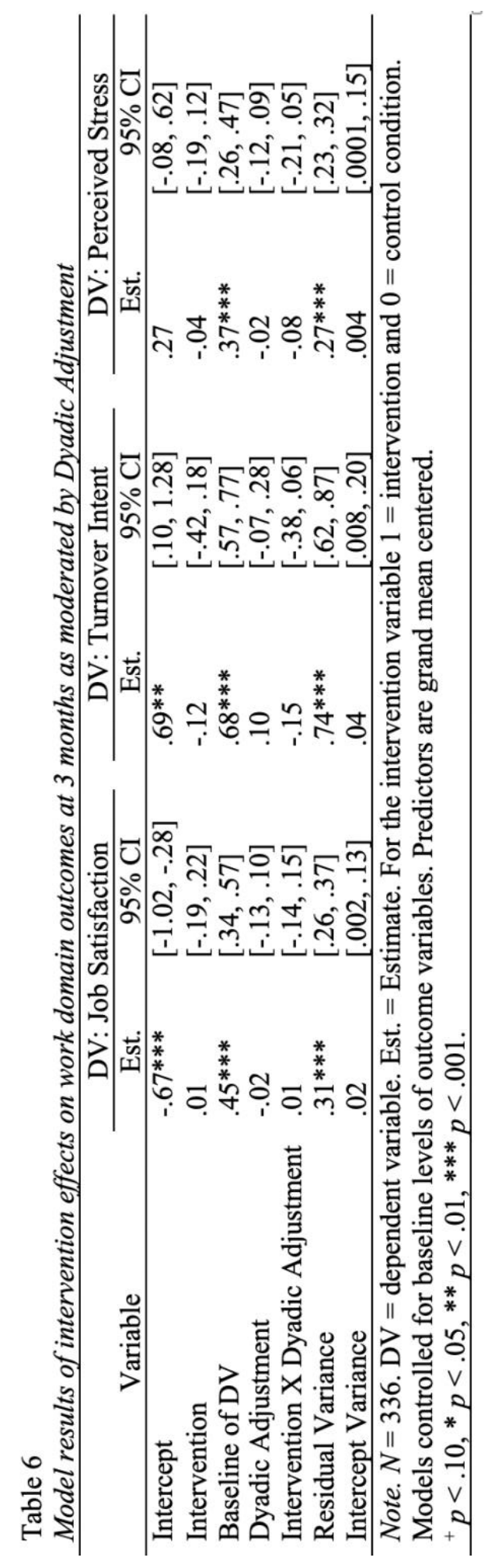




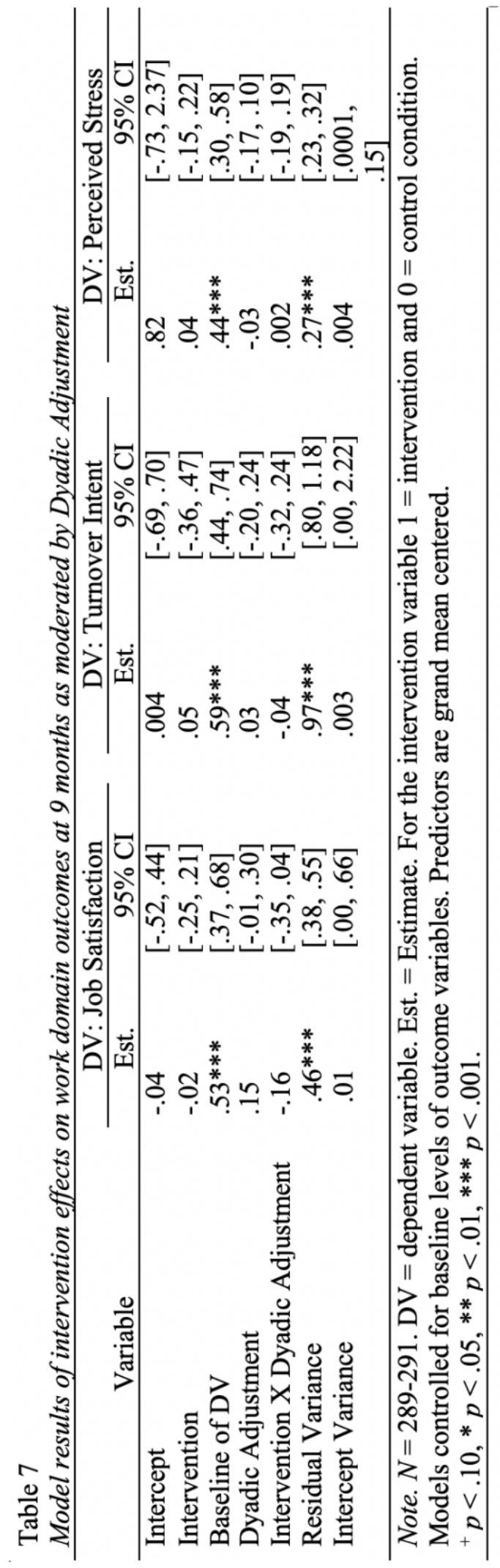




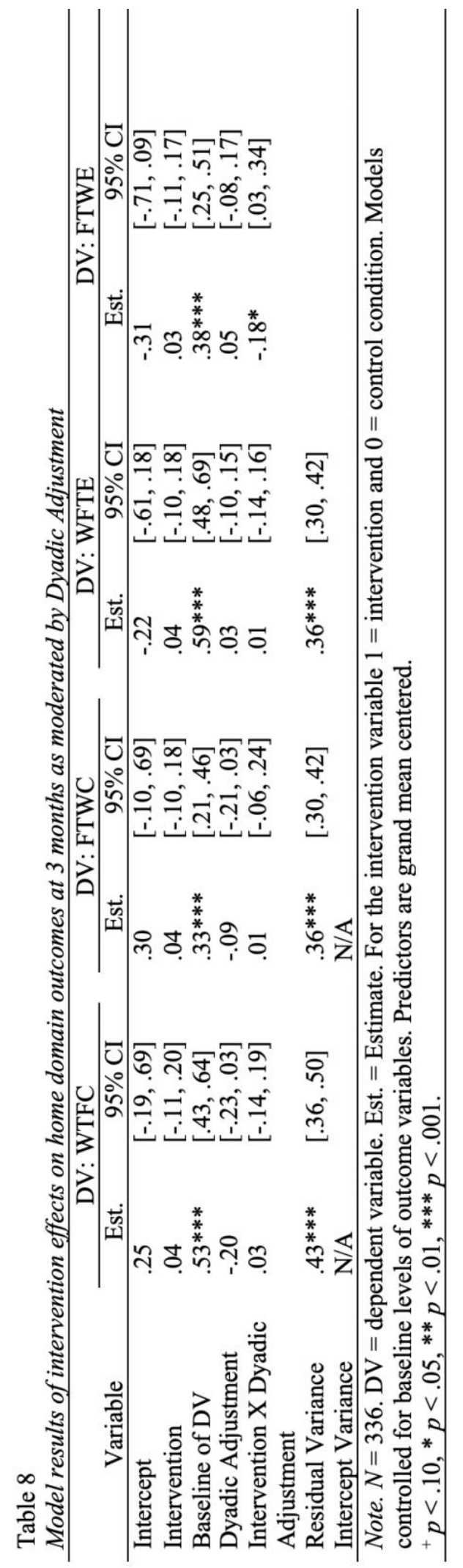




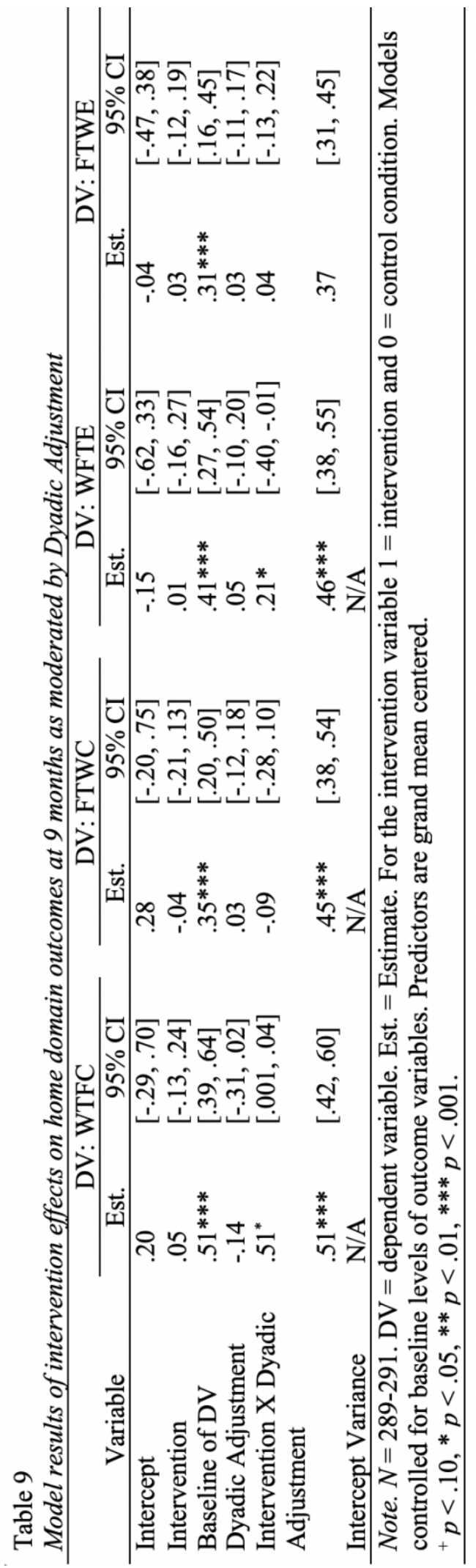




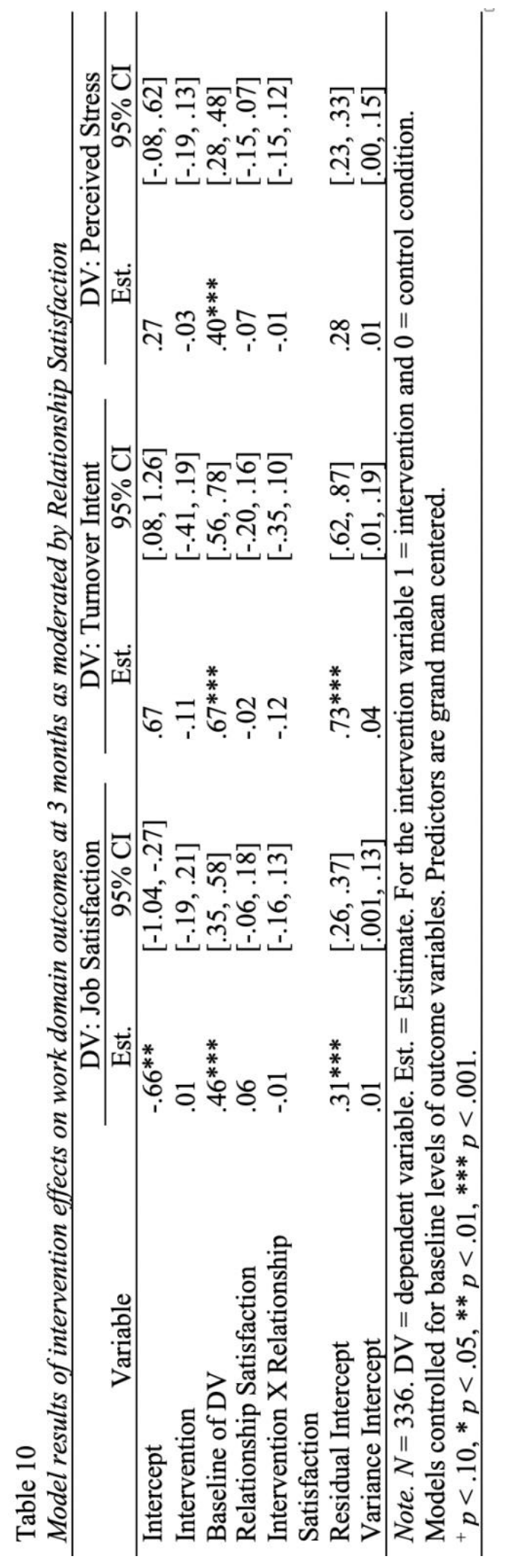




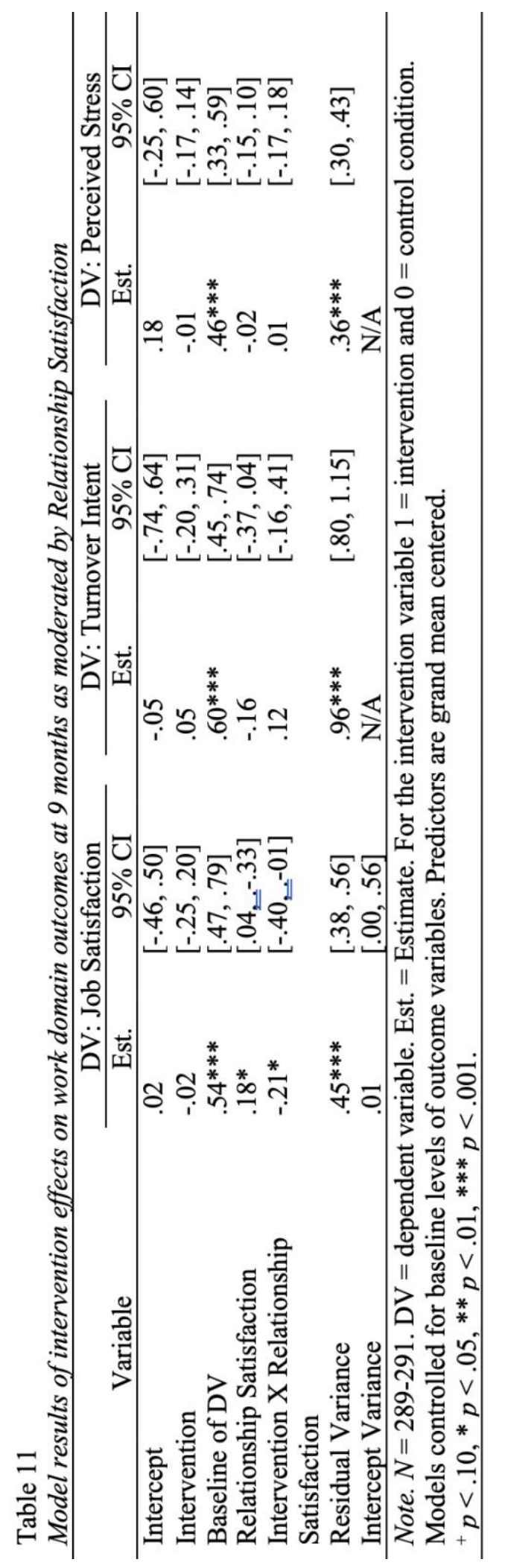




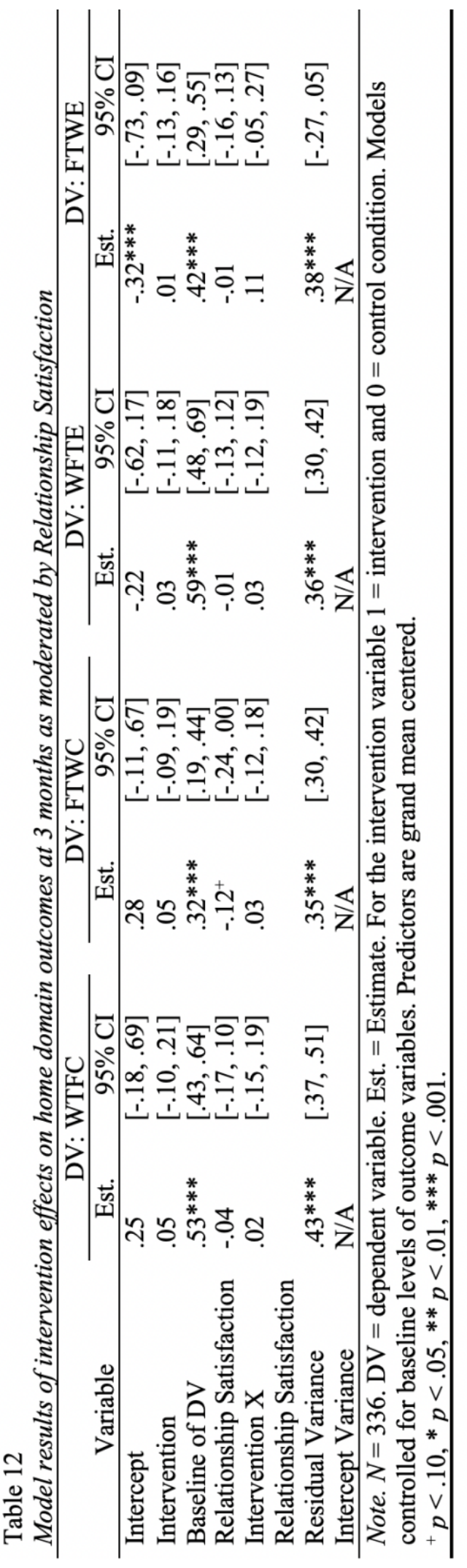




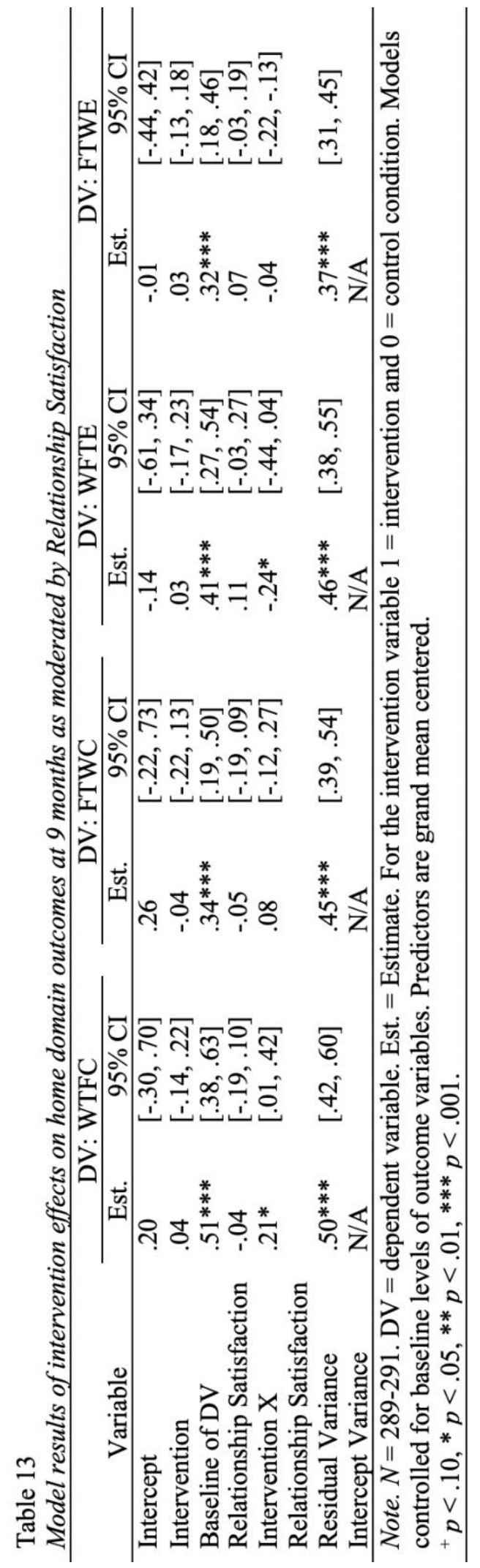




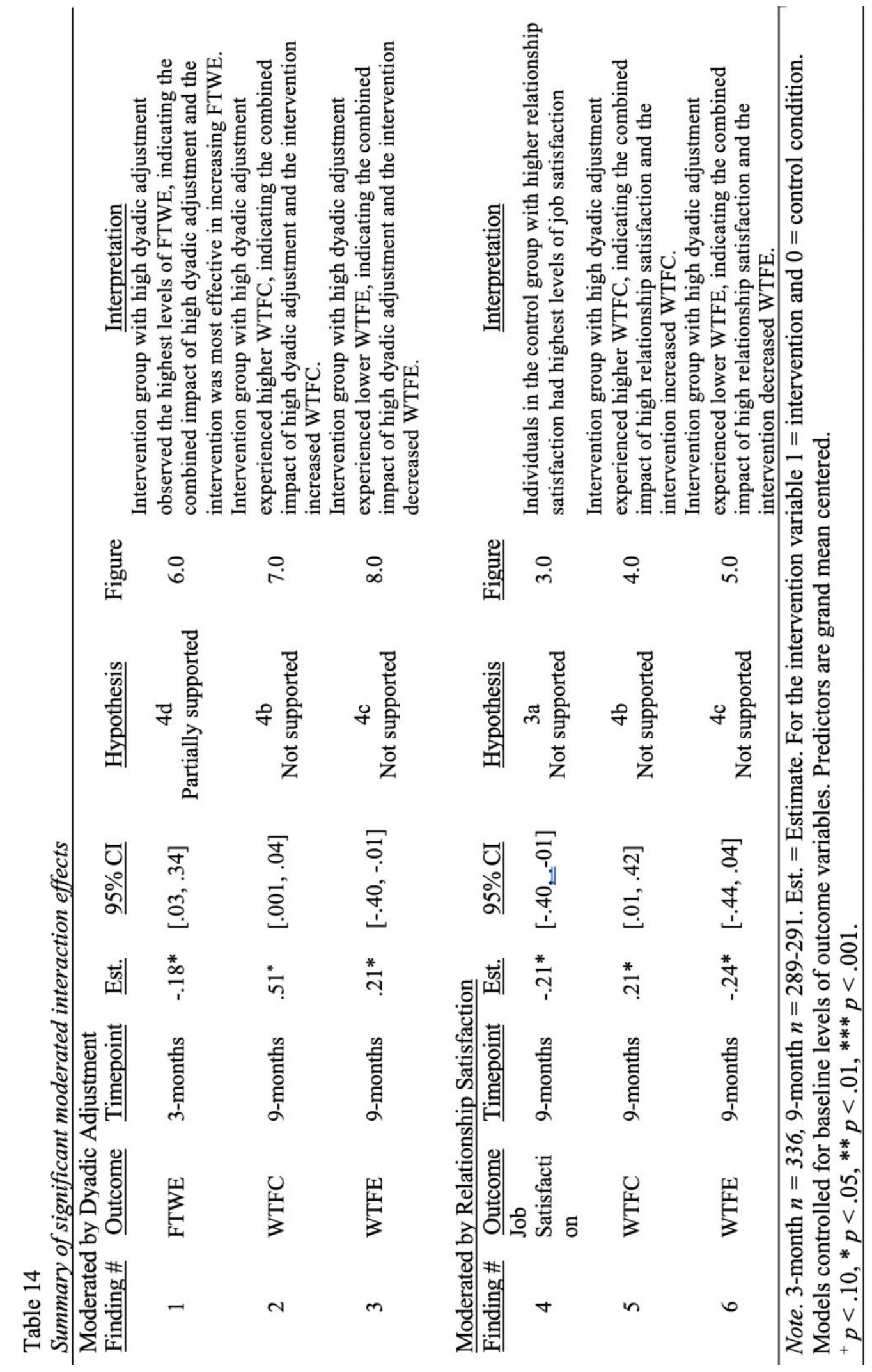




\section{Figures}

Figure 1.0: Conceptual Model Tested by the Proposed Study

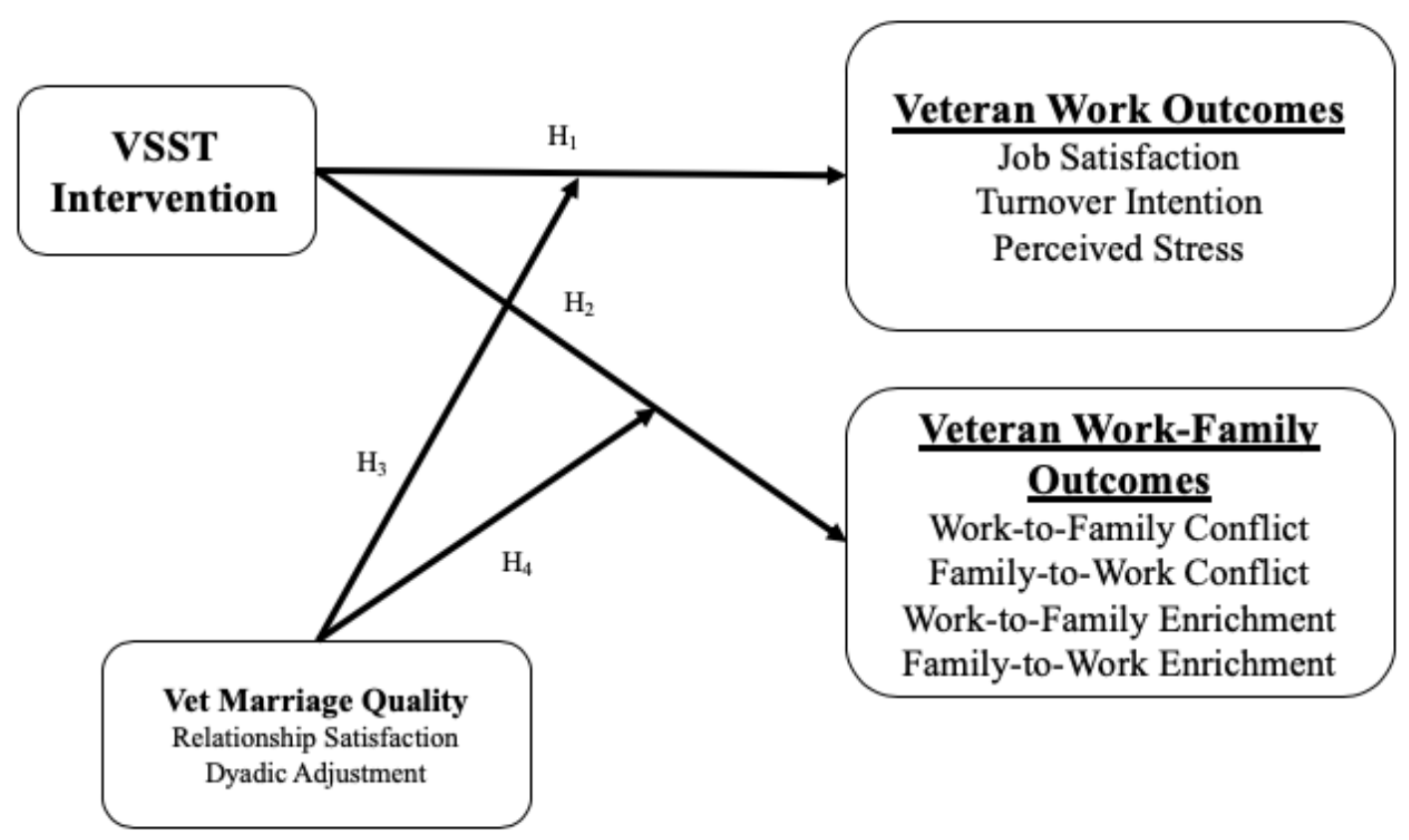


Figure 2.0: Representation of SERVe Project Study Design

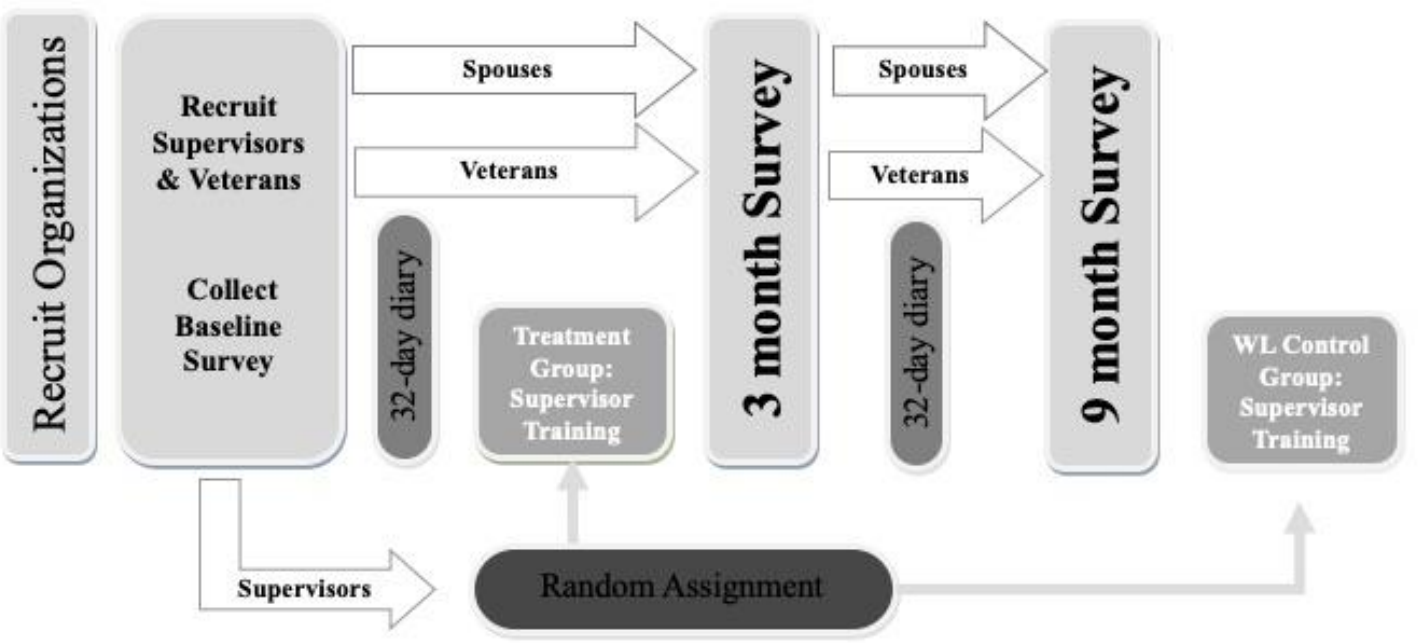


Figure 3.0: Interaction between condition and baseline relationship satisfaction on job satisfaction at 9-months.

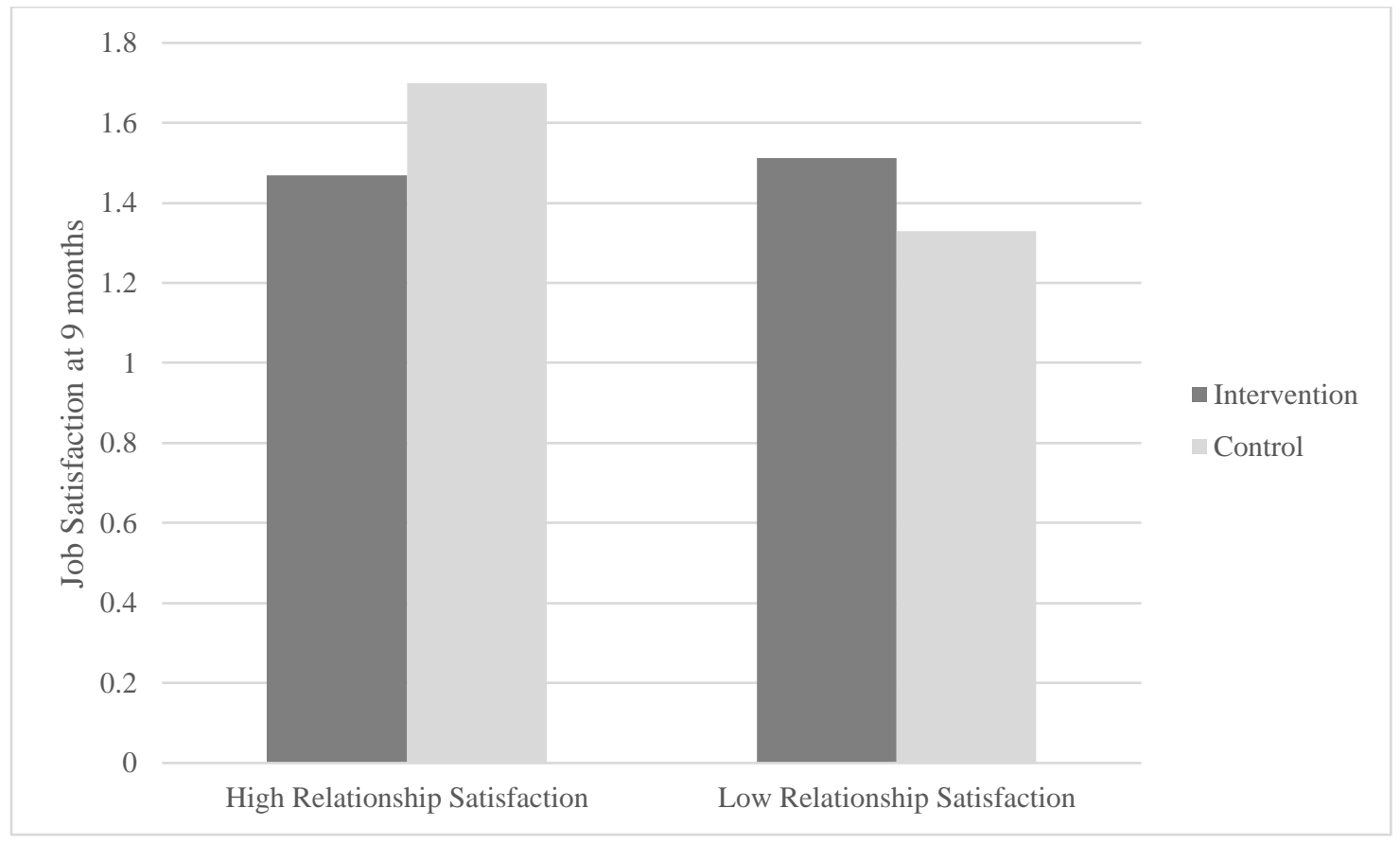


Figure 4.0: Interaction between condition and baseline relationship satisfaction on work-to-family conflict at 9-months.

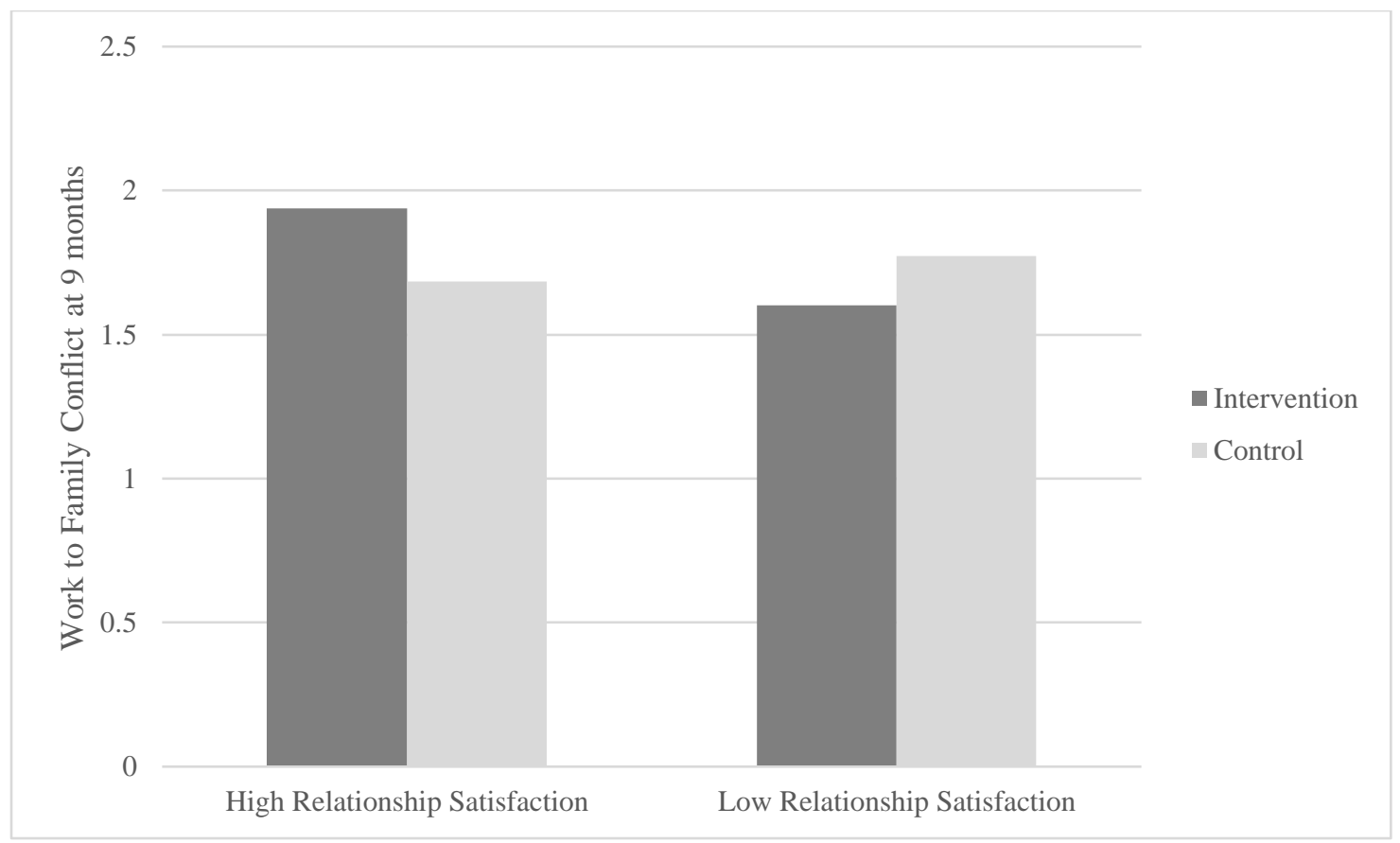


Figure 5.0: Interaction between condition and baseline relationship satisfaction on work-to-family enrichment at 9-months.

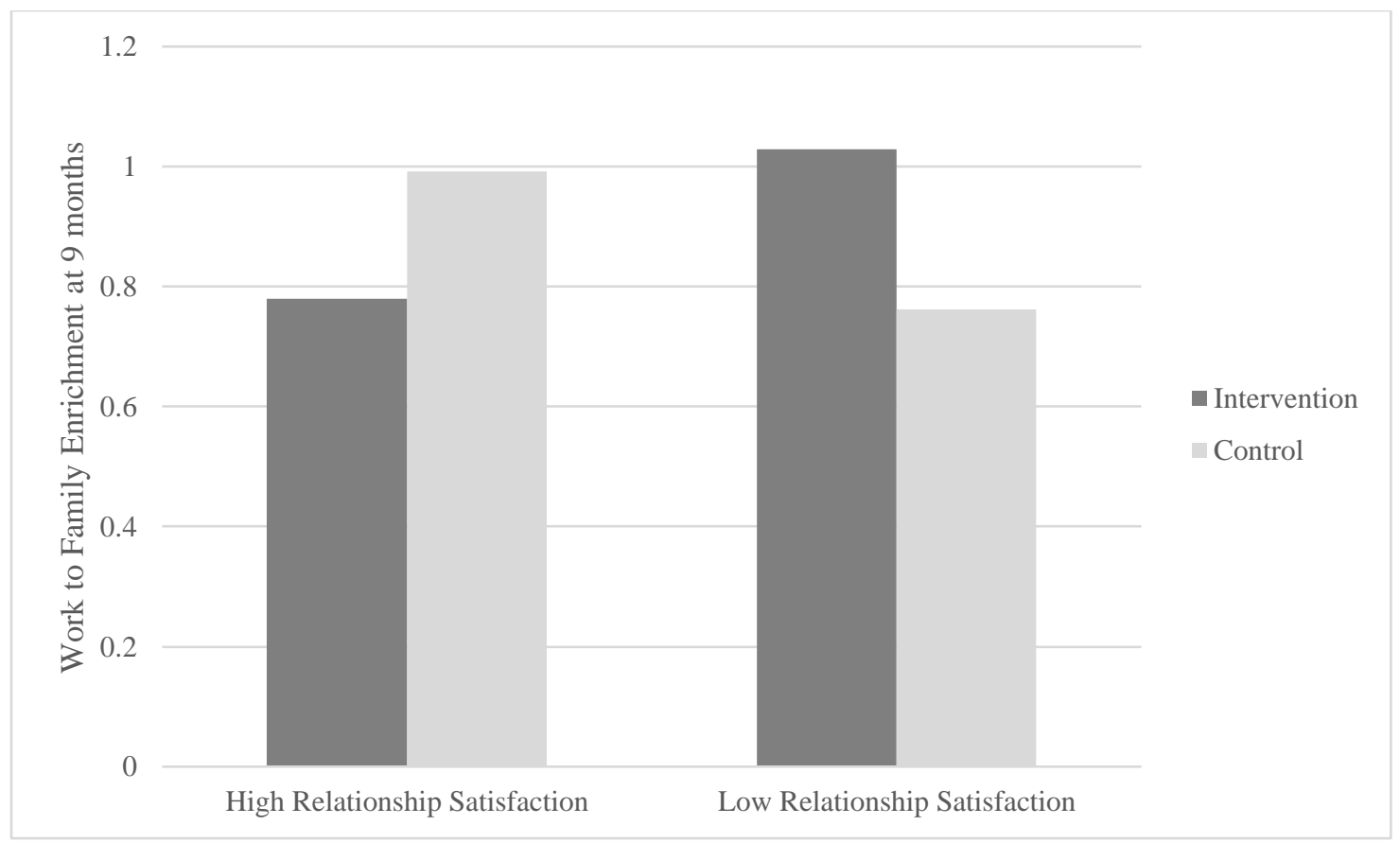


Figure 6.0: Interaction between condition and baseline dyadic adjustment on family-towork enrichment at 3-months.

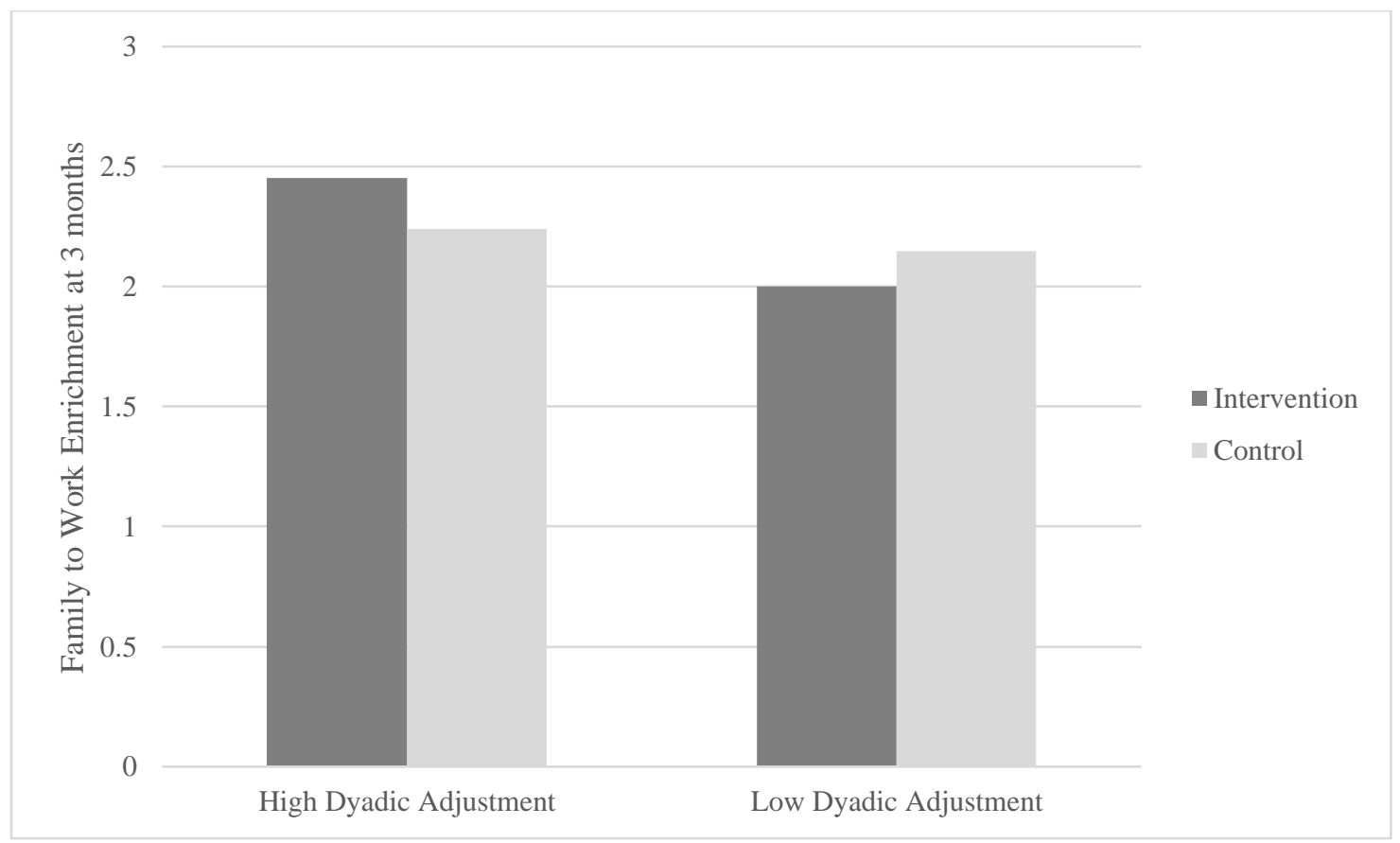


Figure 7.0: Interaction between condition and baseline dyadic adjustment on work-tofamily conflict at 9-months.

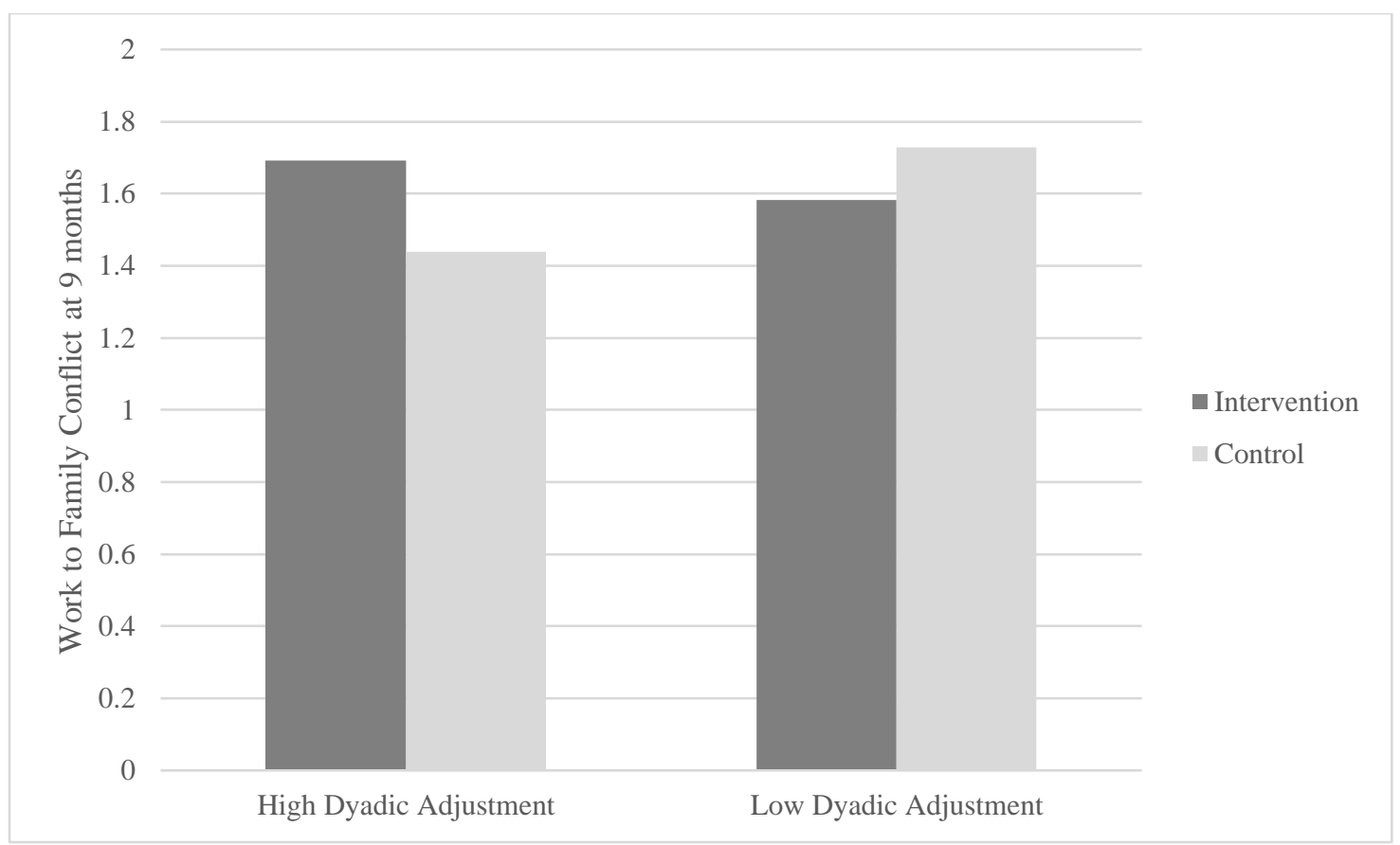


Figure 8.0: Interaction between condition and baseline dyadic adjustment on family-towork enrichment at 9-months.

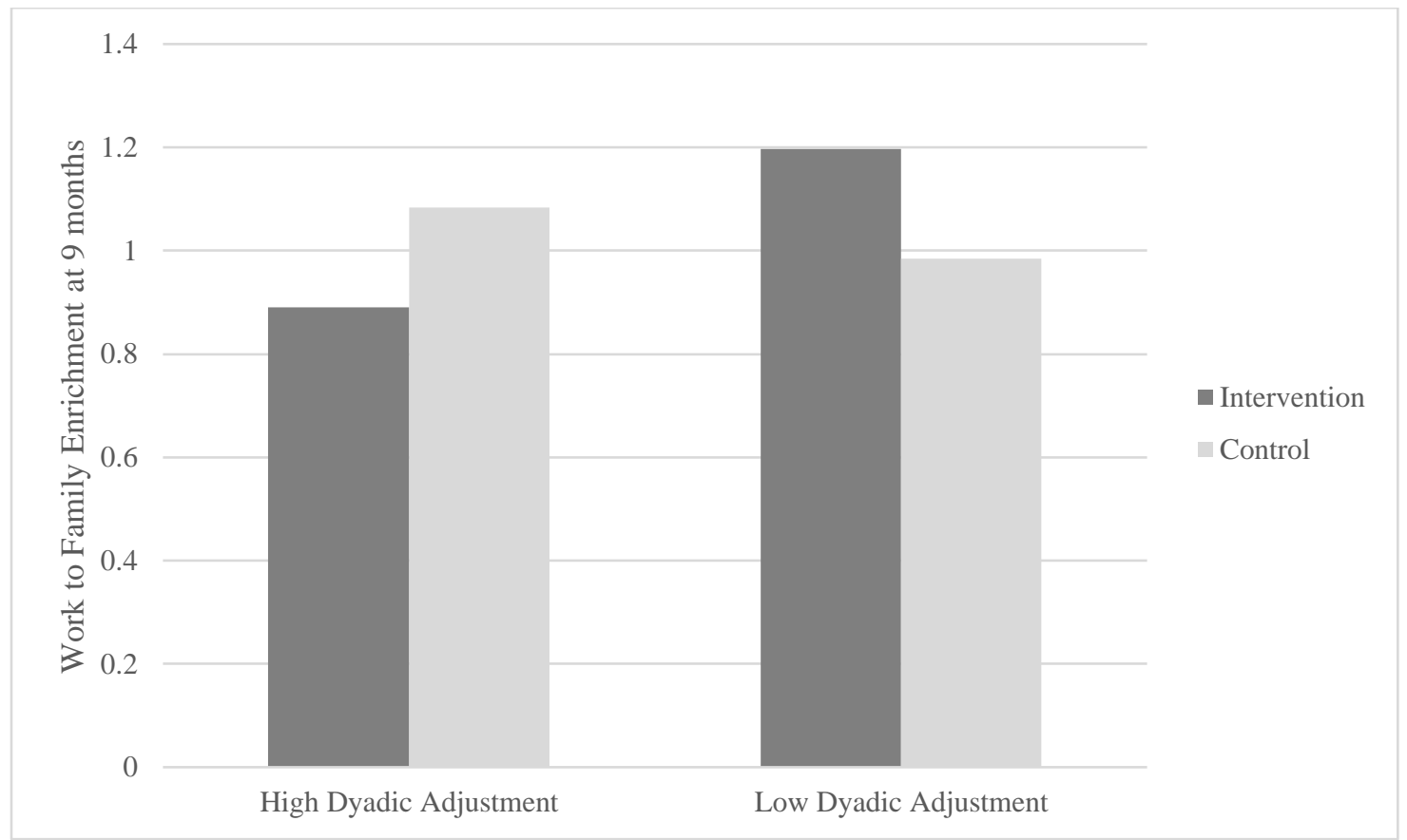




\section{Appendices}

Appendix A: Perceived Stress Scale (PSS; Cohen, Kamarck, \& Mermelstein, 1983)

Appendix B: Work-to-family and Family-to-work conflict measure (Matthews, Kath, \&

Barnes-Darrell,) 2010)

Appendix C: Work-to-family and Family-to-work enrichment measure (Carlson,

Kacmar, Wayne, \& Grzywacz, 2006)

Appendix D: Dyadic Adjustment measure (Hunsley, Best, Lefebvre, \& Vito, 2001) 
Appendix A: Perceived Stress Scale (PSS; Cohen, Kamarck, \& Mermelstein, 1983)

\begin{tabular}{|c|c|c|}
\hline \multicolumn{3}{|c|}{$\begin{array}{l}\text { Instructions: } \\
\text { The questions in this scale ask you about your feelings and thoughts during the PAST } 30 \\
\text { DAYS. In each case, please indicate how often you felt or thought a certain way on the scale } \\
\text { below. }\end{array}$} \\
\hline Item 1 & $\begin{array}{l}\text { In the last month, how often have you felt that you were unable } \\
\text { to control the important things in your life? }\end{array}$ & $\begin{array}{l}1=\text { Never } \\
2=\text { Almost never } \\
3=\text { Sometimes } \\
4=\text { Fairly often } \\
5=\text { Very often }\end{array}$ \\
\hline Item 2 & $\begin{array}{l}\text { In the last month, how often have you felt that you were unable } \\
\text { to control the important things in your life? }\end{array}$ & $\begin{array}{l}1=\text { Very often } \\
2=\text { Fairly often } \\
3=\text { Sometimes } \\
4=\text { Almost never } \\
5=\text { Never }\end{array}$ \\
\hline Item 3 & $\begin{array}{l}\text { In the last month, how often have you felt that things were } \\
\text { going your way? }\end{array}$ & $\begin{array}{l}1=\text { Very often } \\
2=\text { Fairly often } \\
3=\text { Sometimes } \\
4=\text { Almost never } \\
5=\text { Never }\end{array}$ \\
\hline Item 4 & $\begin{array}{l}\text { In the last month, how often have you felt difficulties were } \\
\text { piling up so high that you could not overcome them? }\end{array}$ & $\begin{array}{l}1=\text { Never } \\
2=\text { Almost never } \\
3=\text { Sometimes } \\
4=\text { Fairly often } \\
5=\text { Very often }\end{array}$ \\
\hline
\end{tabular}


Appendix B: Work-to-family and Family-to-work conflict measure (Matthews, Kath, \& Barnes-Darrell,) 2010)

\begin{tabular}{|c|c|c|}
\hline \multicolumn{3}{|c|}{$\begin{array}{l}\text { This section will ask you some questions about how your civilian job relates to your family or } \\
\text { personal life. Please read each statement carefully and fill in the bubble which best represents } \\
\text { your answer. }\end{array}$} \\
\hline \multicolumn{3}{|c|}{ Work-to-Family Conflict } \\
\hline Item 1 & $\begin{array}{l}\text { I have to miss family activities due to the amount of time I } \\
\text { must spend on work responsibilities. }\end{array}$ & \multirow{3}{*}{$\begin{array}{l}1=\text { Almost never } \\
2=\text { Rarely } \\
3=\text { Sometimes } \\
4=\text { Frequently } \\
5=\text { Almost always }\end{array}$} \\
\hline Item 2 & $\begin{array}{l}\text { I am often so emotionally drained when I get home from work } \\
\text { that it prevents me from contributing to my family. }\end{array}$ & \\
\hline Item 3 & $\begin{array}{l}\text { The behaviors I perform that make me effective at work do not } \\
\text { help me to be a better parent and spouse. }\end{array}$ & \\
\hline \multicolumn{3}{|c|}{ Family-to-Work Conflict } \\
\hline Item 4 & $\begin{array}{l}\text { I have to miss work activities due to the amount of time I must } \\
\text { spend on family responsibilities. }\end{array}$ & \multirow{3}{*}{$\begin{array}{l}1=\text { Almost never } \\
2=\text { Rarely } \\
3=\text { Sometimes } \\
4=\text { Frequently } \\
5=\text { Almost always }\end{array}$} \\
\hline Item 5 & $\begin{array}{l}\text { Because I am often stressed from family responsibilities, I have } \\
\text { a hard time concentrating on my work. }\end{array}$ & \\
\hline Item 6 & $\begin{array}{l}\text { Behavior that is effective and necessary for me at home would } \\
\text { be counterproductive at work. }\end{array}$ & \\
\hline
\end{tabular}


VSST INTERVENTION AND MODERATED EFFECTS

Appendix C: Work-to-family and Family-to-work enrichment measure (Carlson, Kacmar, Wayne, \& Grzywacz, 2006)

\begin{tabular}{|c|c|c|}
\hline \multicolumn{3}{|c|}{$\begin{array}{l}\text { Instructions: } \\
\text { For this section, use the statements below to complete each sentence. Please read each } \\
\text { statement carefully and fill in the bubble which best represents your answer. My involvement } \\
\text { with work... }\end{array}$} \\
\hline \multicolumn{3}{|c|}{ Work-to-Family Enrichment } \\
\hline Item 1 & $\begin{array}{l}\text {...helps me to understand different viewpoints and this helps me } \\
\text { be a better family member. }\end{array}$ & \multirow{3}{*}{$\begin{array}{l}1=\text { Strongly } \\
\text { disagree } \\
2=\text { Disagree } \\
3=\text { Neither agree } \\
\text { nor disagree } \\
4=\text { Agree } \\
5=\text { Strongly agree }\end{array}$} \\
\hline Item 2 & $\begin{array}{l}\text {...makes me feel happy and this helps me be a better family } \\
\text { member. }\end{array}$ & \\
\hline Item 3 & $\begin{array}{l}\text {...helps me feel personally fulfilled and this helps me be a better } \\
\text { family member. }\end{array}$ & \\
\hline \multicolumn{3}{|c|}{ Family-to-Work Enrichment } \\
\hline \multicolumn{3}{|c|}{$\begin{array}{l}\text { Instructions: } \\
\text { For this section, use the statements below to complete each sentence. Please read each } \\
\text { statement carefully and fill in the bubble which best represents your answer. My involvement } \\
\text { with family... }\end{array}$} \\
\hline Item 4 & ...helps me acquire skills and this helps me be a better worker. & \multirow{3}{*}{$\begin{array}{l}1=\text { Strongly } \\
\text { disagree } \\
2=\text { Disagree } \\
3=\text { Neither agree } \\
\text { nor disagree } \\
4=\text { Agree } \\
5=\text { Strongly agree }\end{array}$} \\
\hline Item 5 & ...puts me in a good mood and this helps me be a better worker. & \\
\hline Item 6 & $\begin{array}{l}\text {...encourages me to use my work time in a focused manner and } \\
\text { this helps me be a better worker. }\end{array}$ & \\
\hline
\end{tabular}


VSST INTERVENTION AND MODERATED EFFECTS

Appendix D: Dyadic Adjustment measure (Hunsley, Best, Lefebvre, \& Vito, 2001)

\begin{tabular}{|c|c|c|}
\hline \multicolumn{3}{|c|}{$\begin{array}{l}\text { Instructions: } \\
\text { Most people have disagreements in their relationships. Please rate the extent of agreement or } \\
\text { disagreement between you and your spouse/partner based on the scale below. }\end{array}$} \\
\hline Item 1 & Philosophy of life & \multirow{3}{*}{$\begin{array}{l}1=\text { Always disagree } \\
2=\text { Almost always disagree } \\
3=\text { Frequently disagree } \\
4=\text { Occasionally disagree } \\
5=\text { Almost always agree } \\
6=\text { Always agree }\end{array}$} \\
\hline Item 2 & Aims, goals, and things believed important & \\
\hline Item 3 & Amount of time spent together & \\
\hline \multicolumn{3}{|c|}{ How often would you say the following events occur between you and your spouse/partner? } \\
\hline Item 4 & Have a stimulating exchange of ideas & \multirow{3}{*}{$\begin{array}{l}1=\text { Never } \\
2=\text { Less than once a month } \\
3=\text { Once or twice a month } \\
4=\text { Once or twice a week } \\
5=\text { Once a day } \\
6=\text { More often }\end{array}$} \\
\hline Item 5 & Calmly discuss something together & \\
\hline Item 6 & Work together on a project & \\
\hline \multicolumn{3}{|c|}{$\begin{array}{l}\text { The points on the following line represent different degrees of happiness in your relationship } \\
\text { The middle point, "happy," represents the degree of happiness of most relationships. Please } \\
\text { select the place on the scale that best describes the degree of happiness, all things considered } \\
\text { of your relationship. }\end{array}$} \\
\hline Item 7 & $\begin{array}{l}\text { Please select the place on the scale that best } \\
\text { describes the degree of happiness, all things } \\
\text { considered, of your relationship. }\end{array}$ & $\begin{array}{l}0=\text { Extremely unhappy } \\
1=\text { Fairly unhappy } \\
2=\text { A little unhappy } \\
3=\text { Happy } \\
4=\text { Very happy } \\
5=\text { Extremely happy } \\
6=\text { Perfect }\end{array}$ \\
\hline
\end{tabular}

